\title{
Development of Magnetic Compound Fluid Rubber Sensor for Practical Usage on $\gamma$-Irradiation and Energy Harvesting for Broad-Band Electromagnetic Waves
}

\author{
Kunio Shimada ${ }^{*}$, Ryo Ikeda ${ }^{2}$, Hiroshige Kikura ${ }^{2}$, Hideharu Takahashi² \\ ${ }^{1}$ Department of Symbiotic Systems Sciences, Fukushima University, Fukushima, Japan \\ ${ }^{2}$ Research Laboratory for Nuclear Reactors, Tokyo Institute of Technology, Tokyo, Japan \\ Email: *shimadakun@sss.fukushima-u.ac.jp, ikeda.r.ah@m.titech.ac.jp, kikura@lane.iir.titech.ac.jp, \\ htakahashi@lane.iir.titech.ac.jp
}

How to cite this paper: Shimada, K., Ikeda, R., Kikura, H. and Takahashi, H. (2019) Development of Magnetic Compound Fluid Rubber Sensor for Practical Usage on $\gamma$-Irradiation and Energy Harvesting for BroadBand Electromagnetic Waves. World Journal of Mechanics, 9, 205-231.

https://doi.org/10.4236/wjm.2019.99014

Received: August 21, 2019

Accepted: September 23, 2019

Published: September 25, 2019

Copyright $\odot 2019$ by author(s) and Scientific Research Publishing Inc. This work is licensed under the Creative Commons Attribution International License (CC BY 4.0).

http://creativecommons.org/licenses/by/4.0/

\section{(c) (i) Open Access}

\begin{abstract}
We have performed sequential studies on new types of soft rubber for their application as artificial skin in robots and haptic sensors. Based on a proposed electrolytic polymerization method and novel adhesion technique for rubber and a metal that utilizes a metal complex hydrate, we have developed an MCF rubber sensor. This sensor uses a magnetic compound fluid (MCF), natural rubber (NR-latex) or chloroprene rubber latex (CR-latex), and requires the application of a magnetic field. The potential application of the developed sensor in various engineering scenarios and our daily lives is significant. In this regard, we investigated the effects of $\gamma$-irradiation, infrared radiation, microwaves, and a thermal source on the MCF rubber sensor. We established that the MCF rubber is effective enough to be used for power generation of broadband electro-magnetic waves from $\gamma$-rays to microwaves, including the range of the solar spectrum, which is the typical characteristic obtained in the present investigation. The remarkable attribute is that the MCF rubber sensor dose is not degraded by $\gamma$-irradiation. We also demonstrated the effectiveness of the MCF rubber sensor in energy harvesting.
\end{abstract}

\section{Keywords}

$\gamma$-Irradiation, Photovoltaics, Energy Harvesting, Mechanical Property, Thermal Source, Infrared Rays, Electromagnetic Waves, Induced Voltage, Natural Rubber, Chloroprene Rubber, Adhesion, Electrolytic Polymerization, Magnetic Cluster, Magnetic Field, Magnetic Compound Fluid (MCF), Sensing, Robot 


\section{Introduction}

Rubber sensors are indispensable in a variety of engineering applications and affect many aspects of our lives. The elasticity and flexibility of rubber has resulted in the development of numerous outstanding applications. With the objective of further advancement, we have developed and studied the mechanical, electrical and photovoltaic characteristics of soft rubber with hybrid properties of piezoresistivity [1] [2], piezoelectricity [3] and photovoltaics [4]. The soft rubber that is used is usually diene rubber; natural rubber (NR), isoprene rubber (IR), chloroprene rubber (CR), butadiene rubber (BR), nitrile rubber (NBR) or styrene-butadiene rubber (SBR). Given that rubbers have $\mathrm{C}=\mathrm{C}$ bonds and contain water in them so that they can be electrolyzed, they can be solidified using our proposed novel vulcanization approach via electrolytic polymerization [1] [5] [6] [7]. For further progress, we have used our proposed magnetically responsive fluid, magnetic compound fluid (MCF) which has nm-ordered magnetite $\left(\mathrm{Fe}_{3} \mathrm{O}_{4}\right)$ particles and $\mu \mathrm{m}$-ordered metal particles such as $\mathrm{Ni}, \mathrm{Fe}$, etc. [8]. The MCF can be easily obtained by compounding a magnetic fluid (MF) and a metal powder. Based on the application of a magnetic field under the electrolytic polymerization to the soft rubber latex compounded with the MCF (MCF rubber latex), these $\mathrm{Fe}_{3} \mathrm{O}_{4}$ and metal particles aggregate such that many magnetic clusters [9] are created to be aligned along the applied magnetic field lines like needles in the MCF rubber [1]. Therefore, the MCF rubber exhibits electrical and mechanical anisotropy and is also haptic for sensing. The principle of electrolytic polymerization in diene rubber was established on the basis of the ordinary concept a conductive polymer of a plastic type of high polymer solution. However, there have not been any studies whereby the same electrolytic polymerization concept can be applied to rubber. In the case of utilizing NR or CR in the MCF, the MCF rubber becomes highly elastic and flexible due to oleic acid coated on the $\mathrm{Fe}_{3} \mathrm{O}_{4}$ in MF. Based on the aforementioned typical aspects of anisotropy and flexibility, when the MCF rubber is utilized as a sensor, the high-sensitivity and elastic response to any force and heat is feasible enough to consider being developed as an artificial skin. For example, one that is applicable as a substitute for human or robot skin, such as our proposed hybrid skin (H-skin) in our previous studies [10] [11] [12].

The MCF rubber has hybrid properties because its molecules and particles are ionized enough to assume the roles of donor and acceptor of $\mathrm{n}$ - and p-type compound semiconductors, as seen in the photovoltaic field, such as in the case of an organic solar cell. Thus, the MCF rubber has the characteristics that the material of a compound semiconductor is used as particle or powder so that the semiconducting property creates the state of particles dispersion. The detailed principle and the photovoltaic property have been shown in our previous studies [4] [10] [11] [12]. It also can have possibility of reaction to electromagnetic waves including radiation and microwaves, but this has not been demonstrated via experimental investigations as yet. With respect to radiation, the MCF rub- 
ber has many applications in the engineering field of robot sensing in a nuclear reactor building when removing irradiated debris. As for the microwaves, it is also expected that power generation is possible with application in the field of energy harvesting.

The purpose of the series of investigation is to develop an MCF rubber as a practical sensor for various applications in engineering and our daily lives, in addition to robotics. In this report, we clarify that the MCF rubber is effective enough to have applicability in power generation with broadband electromagnetic waves, from $\gamma$-rays to microwaves including the solar spectrum. In addition, the stability of the sensing is also important. In the consecutive report, we mainly deal with the improvement of the sensor's stability of the MCF rubber, in terms of resolving the problem by compounding diene and non-diene rubbers.

We should deal with the MCF rubber as a sensor style which has electrodes because we do not use the type with just a single rubber sheet, except as a sensor style fabricated with electrodes. Moreover, we have proposed a novel adhesion technique to resolve the problem of adhesion between a rubber and metal electrodes without existing electrical and thermal insulation [13]. The current commercial conductive adhesive creates electrical and thermal insulation between the rubber and metal. The proposed novel adhesion technique is such that the MCF rubber with a metal complex hydrate is electrolytically polymerized under the application of a magnetic field, such that the metal electrodes can be adhered to the rubber. During this study, we use our proposed adhesion technique in the fabrication of the MCF rubber.

Regarding electro-magnetic radiation, in the case of utilizing the MCF rubber for sensing in a nuclear reactor building, information on sensing in hot water, and the resistance to the radiation and the water, etc. in it is required. With respect to sensing of $\gamma$-rays in the case of a robot with an installed sensor operating in a nuclear reactor building, there have been many published results [14] [15] [16]. The sensors are divided into non-contact and contact types. Many types of the former have been devised for example, by utilizing ultrasonic wave [17], etc. [18]. The latter is a haptic sensor. However, a sensor made of rubber has not been proposed until recent because rubber tends to degrade. The former also has a fatal problem the resistance to radiation of electronic parts. However, scintillation detectors have reactive materials for radiation so that they utilized as a radiation sensor [19]. However, a scintillation detector made of rubber has not been proposed as yet. If the sensor or scintillator is made of rubber, and in addition, if the rubber is sensitive to a force and temperature under irradiated ambience, these sensors will form a new class of useful sensors in engineering fields: for example, a robot installed with rubber as an artificial outer skin is ideal in terms of working in a nuclear reactor building. However, the degradation of the rubber is a serious problem in that the rubber becomes hard. This has been reported in investigations on silicone rubber [20] and NR [21] as well as the results of the mechanical properties of various kinds of rubber irradiated by $\gamma$-rays [22] [23] 
[24] [25]. Therefore, in the present report, we investigate the effect of $\gamma$-rays on the mechanical properties of an MCF rubber sensor under compression and tension.

Until recently metal oxides have been used in sensing of $\gamma$-rays because of their semiconducting properties and low-cost [26]-[33]. In the present report, we used $\mathrm{TiO}_{2}$ or $\mathrm{ZnO}$, which is involved in the MCF rubber sensor. In addition, there has also been investigations metal complex with $\gamma$-irradiation [34] [35] [36]. The MCF rubber sensor is made with metal complex in the proposed adhesion technique [13]. Therefore, we can also investigate the effect of the metal complex on the MCF rubber sensor for $\gamma$-irradiation, simultaneously. In the present report, we investigate the change of the induced voltage of the MCF rubber sensor with piezo-voltage during irradiation with $\gamma$-rays using ${ }^{60} \mathrm{Co}$. We also investigate the effect of $\gamma$-rays on the cyclic voltammogram of the MCF rubber sensor because it is important to investigate the relation between the current and rest potential under the $\gamma$-irradiation [37] [38] [39] [40] [41].

Next, energy harvesting is significant enough to resolve energy problems using a new technique except for renewable energy. We can utilize any energy source disposed and hidden in our daily lives. Then, as we can realize that the energy harvesting mainly eventuates in four sources: solar, thermal, oscillating, electro-magnetic wave generations. In the present report, we adopt the experimental subject as a practical usage style of energy harvesting. For example, we can use a heating plate, microwave oven and infrared heater, which are familiar in our daily lives. To obtain power generation, it is important to use the sensing of the MCF rubber sensor. To investigate the possibility of energy harvesting to clarify the sensibility for the aforementioned four sources. The first source (solar) was dealt with as photovoltaics of the MCF rubber sensor in the range of visible and ultraviolet light in our previous studies [4] [10] [11] [12]. Therefore, in the present report, we investigate the effect of infrared light on the MCF rubber sensor using an infrared heater, which has connection with the second source (thermal). The second source is also important subject, although few studies have been conducted utilizing a flexible material such as rubber [42]. Therefore, in the present report, we also investigated the effect of the thermal energy on the MCF rubber sensor using a heating plate. The third source (oscillating) can almost be guessed by the results of piezoelectricity of MCF rubber in our previous studies [3] because the third source is relevant to piezoelectricity. In general, we should investigate the effect of vibration on the frequency characteristics of the piezoelectricity precisely. However, we will describe the results in another report because of limiting space of the present report. Regarding the fourth source (electro-magnetic wave), there have been a few current investigations on a flexible material such as rubber [43] [44] [45] [46]. In contrast, in the previous our study we clarified the effect of microwave on a MCF rubber sheet made of silicone oil rubber solidified under drying ambience [47]. However, the MCF rubber involving diene type rubber has not been conducted on. In the 
present report, we investigate the effect of the microwave on the MCF diene rubber sensor by using a microwave oven. From these investigations, we clarify the effective possibility of the MCF rubber sensor in the energy harvesting.

\section{2. $\gamma$-Irradiation}

\subsection{Irradiation Effect}

Firstly, we investigate the irradiation effect of an MCF rubber sensor using the irradiation facility in the Laboratory for Advanced Nuclear Energy, Tokyo Institute of Technology in Japan as shown in Figure 1. The $\gamma$-rays was irradiated from a ${ }^{60} \mathrm{Co}$ source. The absorbed dose rate used was changed by varying the distance between the source to the specimen, $90 \mathrm{~Gy} / \mathrm{h}$ and $230 \mathrm{~Gy} / \mathrm{h} /$.

The specimen set on a table is MCF rubber sensor which was made using our proposed adhesion technique [13] as shown in Figure A1 in Appendix. The electrical wires from the MCF rubber sensor were placed to the outside of the irradiation chamber, and the induced voltage and electric current were measured. The sensor consisted of MCF rubber liquid with hydrate as $1 \mathrm{~g}$ carbonyl Ni powder with particles on the order of microns with bumps on the surface (No. 123, Yamaishi Co., Ltd., Noda, Japan), 0.75 g MF with 40 wt $\% \mathrm{Fe}_{3} \mathrm{O}_{4}$ (W-40, Ichinen-Chemicals Co., Ltd., Shibaura, Japan), 3 g NR-latex (Ulacol, Rejitex Co., Ltd., Atsugi, Japan), 3 g CR-latex (671A, Showa Denko Co. Ltd., Tokyo, Japan), $0.5 \mathrm{~g} \mathrm{TiO}_{2}$ (Anatase type, Fujifilm Wako Pure Chemical Co., Ltd., Osaka, Japan), and $0.5 \mathrm{~g}$ hydrates $\mathrm{Na}_{2} \mathrm{WO}_{4} \cdot 2 \mathrm{H}_{2} \mathrm{O}$ (Fujifilm Wako Pure Chemical Co., Ltd., Osaka, Japan), and MCF rubber without hydrate as $3 \mathrm{~g}$ Ni powder, $0.75 \mathrm{~g} \mathrm{MF}$ (W-40), $3 \mathrm{~g}$ NR-latex, $3 \mathrm{~g}$ CR-latex $(671 \mathrm{~A})$, and $0.5 \mathrm{~g} \mathrm{TiO}_{2}$. The same weight as CR-latex (671A) was used in the case of CR-latex (400), and the same weight as $\mathrm{TiO}_{2}$ in the case of $\mathrm{ZnO}$. $\mathrm{TiO}_{2}$ and $\mathrm{ZnO}$ are the dopants in the MCF rubber. The sensor has an area of approximately $19 \mathrm{~mm} \times 22 \mathrm{~mm}$ and a thickness of approximately $2 \mathrm{~mm}$, despite individual difference.

The induced voltage by irradiation is shown in Figure 2. The figures show the long-time changing from continuous irradiation. At the initial period of the irradiation process as shown by " $\mathrm{A}$ " in Figure $2(\mathrm{~b})$ and Figure $2(\mathrm{~d})$, the induced voltage has a radically increasing peak, and then decreases. After the period " $A$ ",

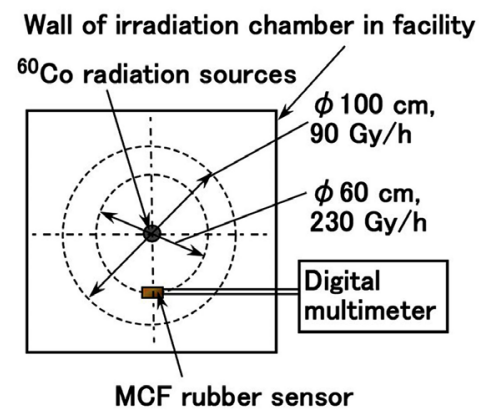

Figure 1. Schematic diagram depicting layout for $\gamma$-irradiation and geometric relationship. 


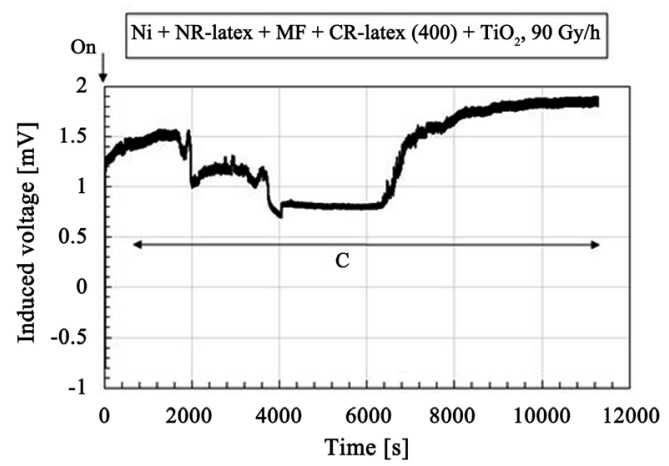

(a)

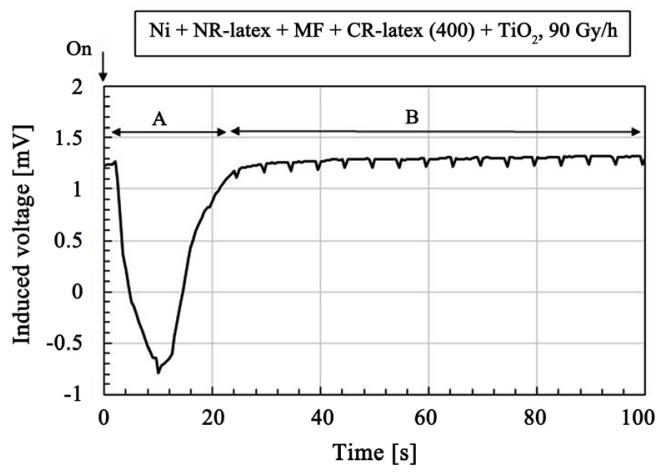

(b)

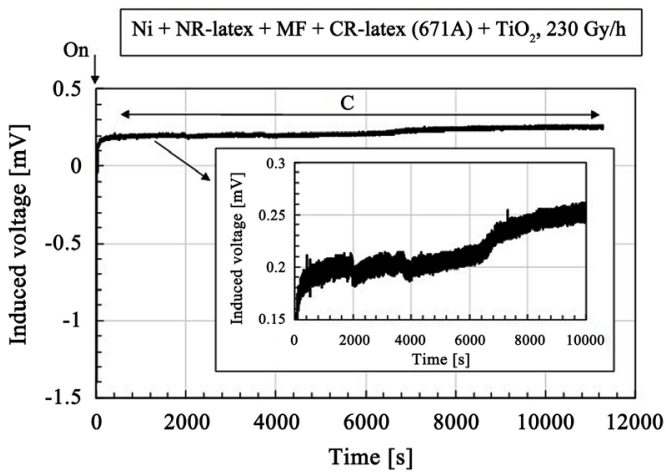

(c)

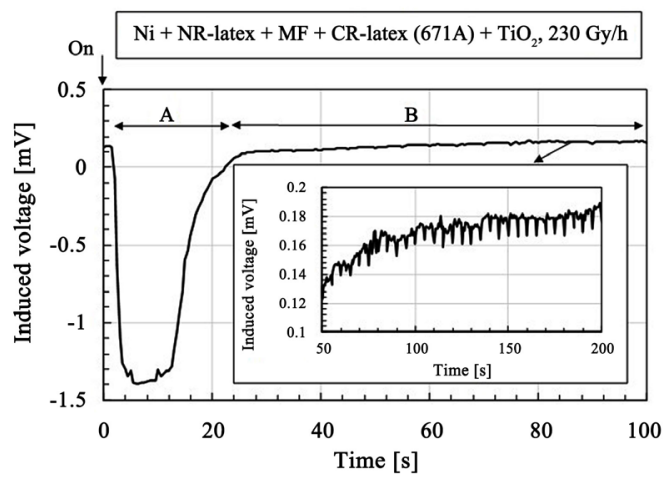

(d)

Figure 2. Change of induced voltage with time for $\gamma$-irradiation: (a) and (b) using CR-latex(400) and $\mathrm{TiO}_{2}$; (c) and (d) using CR-latex(671A) and $\mathrm{TiO}_{2}$; (b) and (d) is detail of (a) and (c) respectively. 
as shown by "B" in Figure 2(b) and Figure 2(d), it changes with fine regular oscillations during the long period. At the longer elapsed time, it changes in a disorderly manner by first increasing and then decreasing as shown by " $C$ " in Figure 2(a) and Figure 2(c). Regarding the period over "A" and "B", FFT analysis was performed on the changing voltage and the results are shown in Figure 3 and Table 1. The dominant fundamental has multiples of the frequency of 200 $\mathrm{mHz}$. The fine regular oscillation at " $\mathrm{B}$ " is based on the typical frequency. These phenomena are independent of the kinds of CR-latex, dopants, and irradiation intensity. The results will be discussed later.

From those results, we can attempt to predict the physical model of irradiation in the MCF rubber sensor as shown in Figure 4. With respect to the phenomenon represented by " $A$ " in Figure $2(b)$ and Figure $2(d)$ and $V_{P-P}$ at " $B$ " in Table 1, when subject to irradiation by $\gamma$-rays, the electrons in the innermost inner-shell can jump to the conduction band as indicated by the green-colored arrow "b" in Figure 4(a). This is in contrast to ordinary electrons jumping from the outermost outer-shell due to irradiation by visible and ultraviolet light, heat, etc. as designated by the blue-colored arrow "a" in Figure 4(a). As a result of the depletion region in the inner-shell, the electrons in adjacent inner-shells fall into the depletion region. The fall into the inner shell sequentially occurs causing an avalanche of outer shell electrons as designated by the red-colored arrow " $c$ " in Figure 4(a). The same phenomenon has been elucidated and the electrons jump from the inner shell in the case of $\mathrm{TiO}_{2}$ due to irradiation by X-rays [39]. The electrons in the inner-shell can be possibly induced to jump because the frequency of $\gamma$-rays is higher than that of X-rays. However, many studies have been conducted on the radiation effect of metal oxide as well as $\mathrm{TiO}_{2}$ due to $\gamma$-ray irradiation [26]-[33]. In addition, a study has also been conducted on the effect of $\gamma$-radiation on $\mathrm{Fe}$ [29]. The MCF rubber sensor used included $\mathrm{Fe}$ as seen from $\mathrm{Fe}_{3} \mathrm{O}_{4}$. Moreover, several studies have been conducted on $\gamma$-irradiation of metal complex [34] [35] [36]. Therefore, $\mathrm{Na}_{2} \mathrm{WO}_{4} \cdot 2 \mathrm{H}_{2} \mathrm{O}$ used in the MCF rubber sensor for the adhesion of electrodes to the rubber has a radiation effect. As previously described, the MCF rubber sensor likely has a $\gamma$-irradiation effect.

With respect to the phenomenon represented by " $B$ " in Figure 2(b) and Figure 2(d), the following causes can be inferred. Based on the electron's transition from the innermost inner shell, an increasing voltage is generated. Therefore, molecules and particles are ionized anionic as indicated by "b" in Figure 4(b). On the contrary, in the outermost outer shell, the electron in the conduction band enters a hole occurred by sequential avalanche electrons. In addition, the electrons from the increasing anionic molecules and particles move away as shown in "c" in Figure 4(b). As a result, these electron motions induce a decreasing voltage. Finally, there is a balance between these two increasing and decreasing voltages and the induced voltage typical oscillates with a frequency multiple of $200 \mathrm{mHz}$ as shown in Figure 3 and Table 1. Furthermore, the physical model to explain this interesting phenomenon should be further investigated. 
Table 1. Results of Figure 2 and Figure 3 via FFT analysis; $V_{\text {P-p }}$ is mean value during "B".

\begin{tabular}{cccc}
\hline & Dominant Frequency $[\mathrm{mHz}]$ & Spectrum $[\mathrm{dB}]$ & $\mathrm{V}_{\mathrm{p}-\mathrm{p}}$ at B $[\mathrm{mV}]$ \\
\hline & 1.9531 & 4.912 & \\
Figure 2(a) \& & 199.22 & -36.418 & 0.143 \\
Figure 2(b) & 400.39 & -35.943 & \\
& 599.61 & -35.782 & \\
& 0.00 & -13.957 & 0.030 \\
Figure 2(c) \& & 199.22 & -52.224 & \\
Figure 2(d) & 400.39 & -52.297 & \\
& 599.61 & -53.467 & \\
\hline
\end{tabular}

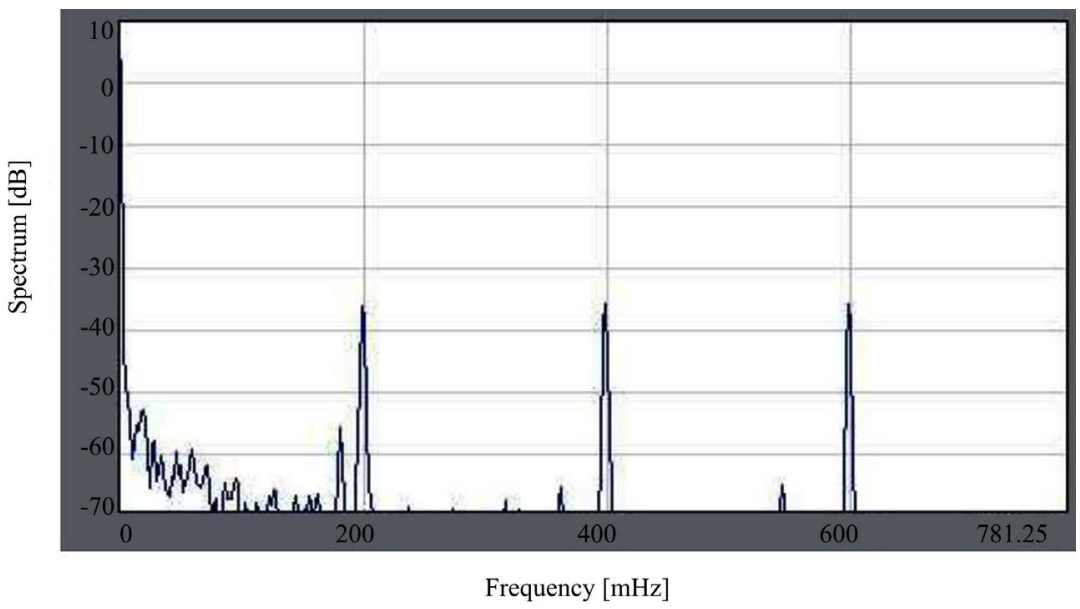

Figure 3. FFT frequency spectrum for Figure 2(a).

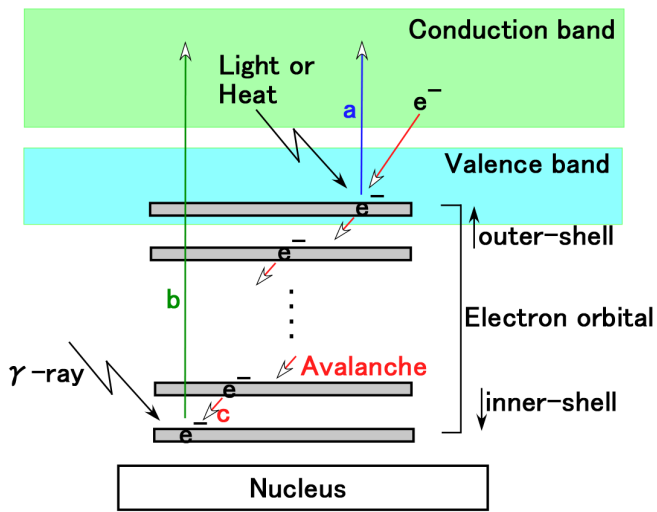

(a)

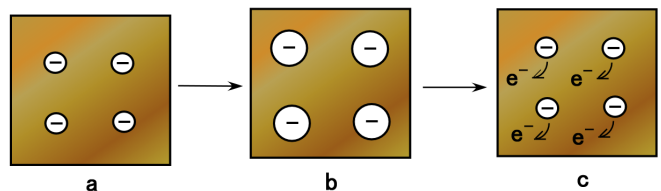

(b)

Figure 4. Physical model of $\gamma$-irradiation effect on MCF rubber sensor: (a) as for initial period by $\gamma$-irradiation as shown by " $A$ " in Figure 2(b) and Figure 2(d); (b) for subsequent period after initial period by $\gamma$-irradiation as shown by "B" in Figure 2(b) and Figure 2(d). 
Figure 5 shows the induced voltage due to intermittent irradiation and off. In Figure 5(a) and Figure 5(b), the constituent of the MCF rubber sensor was the same as the one in Figure 2. In Figure 5(c) and Figure 5(d), the sensor included water and consisted of MCF rubber liquid with hydrate as $1 \mathrm{~g} \mathrm{Ni}, 0.75 \mathrm{~g} \mathrm{MF}$ (W-40), 6 g NR-latex, 3 g CR-latex (671A), $0.5 \mathrm{~g} \mathrm{TiO}_{2}, 0.5 \mathrm{~g} \mathrm{Na}_{2} \mathrm{WO}_{4} \cdot 2 \mathrm{H}_{2} \mathrm{O}$, and $3 \mathrm{~g}$ water, and MCF rubber without hydrate as $3 \mathrm{~g} \mathrm{Ni}, 0.75 \mathrm{~g} \mathrm{MF}$ (W-40), $6 \mathrm{~g}$ NR-latex, $3 \mathrm{~g}$ CR-latex (671A), $0.5 \mathrm{~g} \mathrm{TiO}_{2}$, and $3 \mathrm{~g}$ water. The enhancement of the induced voltage via irradiation is due to the inversion of the electrodes of the MCF rubber sensor, and the results indicate that the voltage due to the motion of the electrons is maintained as described in Figure 4. The $\gamma$-irradiation effect can be repeated many times. However, $\mathrm{V}_{\mathrm{P}-\mathrm{P}}$ for Figure $5(\mathrm{~b})$ is $0.077 \mathrm{mV}$, and $\mathrm{V}_{\mathrm{p}-\mathrm{p}}$ for Figure $5(\mathrm{~d})$ is $0.256 \mathrm{mV}$, compared to $\mathrm{V}_{\mathrm{p}-\mathrm{p}}$ in Figure $2(\mathrm{~b})$ and Figure 2(d). The effect of $\gamma$-rays on the wettability of $\mathrm{TiO}_{2}$ has been highlighted in other studies [37] [38] [40]; $\gamma$-irradiation effect is increased in the presence of water. Therefore, for $\mathrm{V}_{\mathrm{P}-\mathrm{P}}$ of the oscillation at "B" such as in Figure 2(b) and Figure 2 (d), it increases because of the water.

We carefully consider the incremental enhancement of the induced voltage with the progression of time. This is dependent on the stability of the internal physical phenomenon of the MCF rubber sensor. The details will be left to a consecutive report. Therefore, the slowly increasing induced voltage is irrelevant to the aforementioned qualitative results.

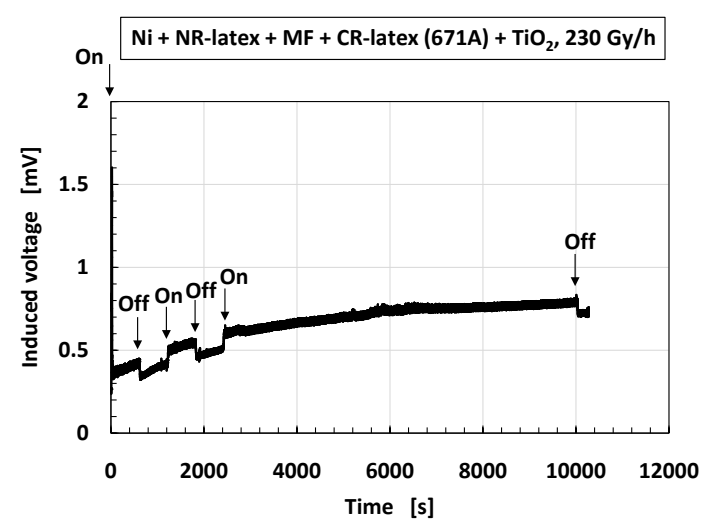

(a)

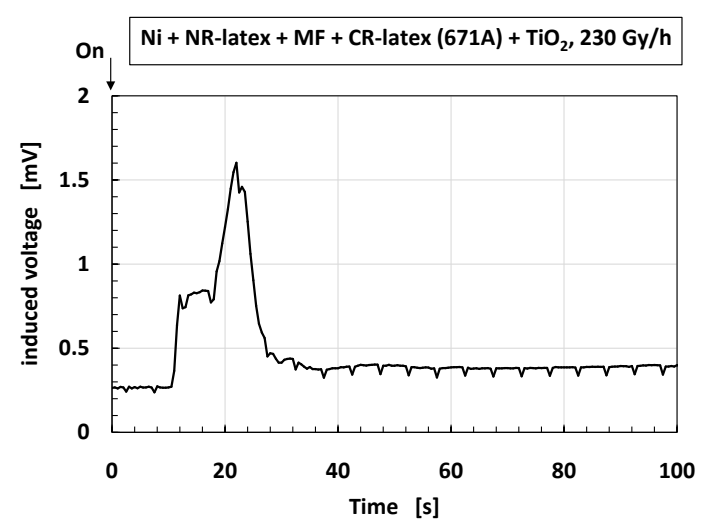

(b) 


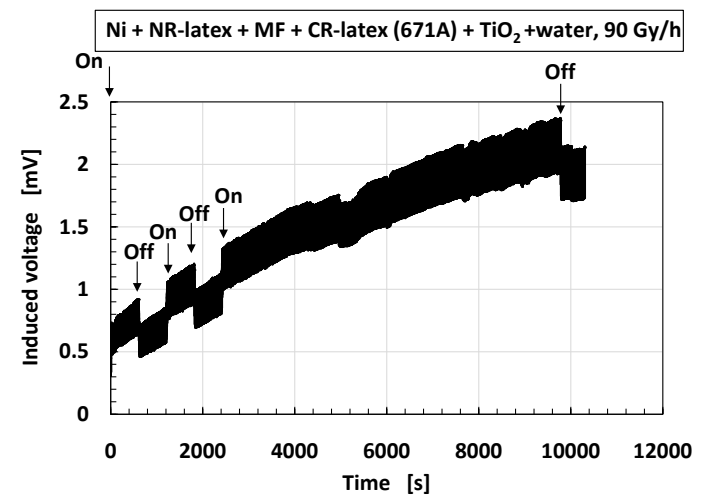

(c)

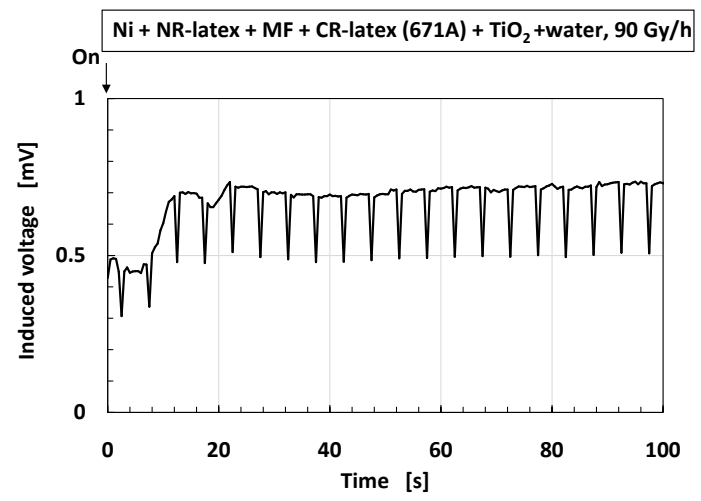

(d)

Figure 5. Change of induced voltage by $\gamma$-irradiation: (a) and (b) without including water at $230 \mathrm{~Gy} / \mathrm{h}$; (c) and (d) with including water at $90 \mathrm{~Gy} / \mathrm{h}$; (b) and (d) are detail of (a) and (c), respectively.

Next, we investigated the cyclic voltammogram as shown in Figure 6. The MCF rubber sensor consisted of the same mass of each constituent as that of Figure 2. However, for the other dopants in the production of sensor, the same weight as $\mathrm{TiO}_{2}$ or $\mathrm{ZnO}$ was used. $\mathrm{KI}+\mathrm{I}_{2}$ was solution compounded with $3.3 \mathrm{~g} \mathrm{I}_{2}$ in a solution of $40 \mathrm{~g}$ potassium iodide $\mathrm{KI}$, and $60 \mathrm{~g}$ water. We used a potentiostat (HA-151B, Hokuto Denko Co. Ltd., Tokyo, Japan) at $50 \mathrm{mHz}$ scan rates in the potential domain from -1.5 to $1.5 \mathrm{~V}$. As shown in Figure 6(d), in the case of irradiation, $I_{\max }$ becomes small on the order of $\mathrm{ZnO}, \mathrm{TiO}_{2}$ and $\mathrm{LiNbO}_{3}$, when the electric current is compared for various kinds of dopant. Therefore, to compare the cyclic curves, for irradiation to the one for non-irradiation, the voltage and electric current are nondimensionalized $V^{*}$ and $I^{*}$ by $V_{\max }$ and $I_{\max }$, respectively: $V_{\max }=1.494 \mathrm{~V}$ and $I_{\max }=0.878 \mathrm{~mA}$ for Figure 6(a) [48], $V_{\max }=1.492 \mathrm{~V}$ and $I_{\max }=$ $1.786 \mathrm{~mA}$ for Figure 6(b) [48], $V_{\max }=1.491 \mathrm{~V}$ and $I_{\max }=0.021 \mathrm{~mA}$ for Figure 6(c).

From these cyclic curves, we can obtain the short circuit current and the open circuit voltage as shown in Table $2 . \mathrm{TiO}_{2}$ is a photocatalyst and so it is typically used in solar cells and has the role of electron transport. $\mathrm{ZnO}$ and $\mathrm{LiNbO}_{3}$ are effective materials for inducing the piezoelectric effect and are used in piezo-elements. Aluminum nitride, AlN has high thermoconductivity and electrical 
insulation so that it is also used in piezo-elements. As seen from the results of Figure 6 and Table 2, in the case where a dopant is used in a piezo-element, the electric current in the cyclic voltammogram has a lower tendency. $\mathrm{KI}+\mathrm{I}_{2}$ is a typical dopant of an acceptor.

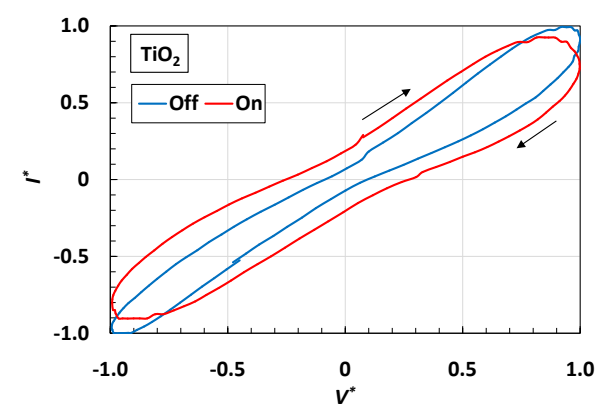

(a)

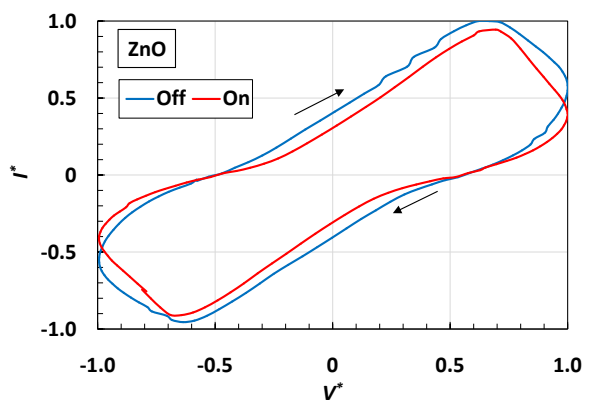

(b)

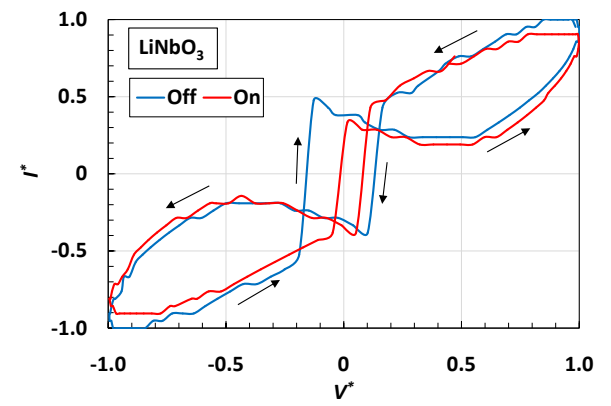

(c)

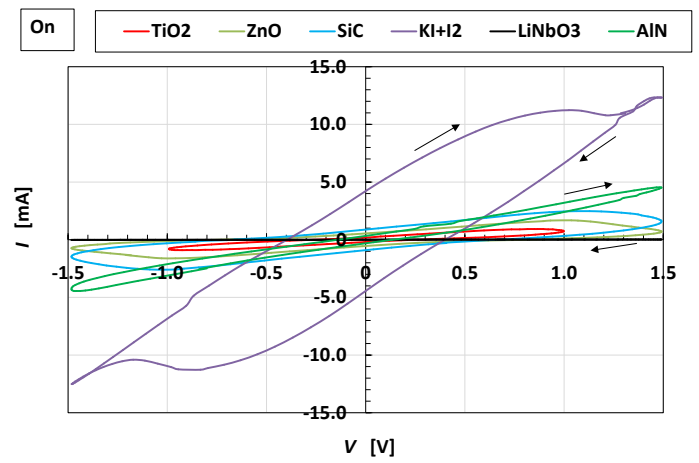

(d)

Figure 6. Cyclic voltammogram of MCF rubber sensor by $\gamma$-irradiation: (a) $\mathrm{TiO}_{2}$ [48]; (b) $\mathrm{ZnO}$ [48]; (c) $\mathrm{LiNbO}_{3}$; (d) under $\gamma$-irradiation. 
Table 2. Short circuit current and open circuit voltage of MCF rubber sensor with and without $\gamma$-irradiation.

\begin{tabular}{ccccc}
\hline & \multicolumn{2}{c}{ Short Circuit Current $[\mathrm{mA}]$} & \multicolumn{2}{c}{ Open Circuit Voltage $[\mathrm{V}]$} \\
\hline Dopant & Off & On & Off & On \\
$\mathrm{TiO}_{2}$ & 0.063 & 0.168 & 0.136 & 0.400 \\
$\mathrm{ZnO}$ & 0.677 & 0.569 & 0.789 & 0.777 \\
$\mathrm{SiC}$ & 1.186 & 0.834 & 0.676 & 0.662 \\
$\mathrm{KI}+\mathrm{I}_{2}$ & 4.810 & 4.359 & 0.428 & 0.366 \\
$\mathrm{LiNbO}_{3}$ & 0.007 & 0.007 & 0.217 & 0.085 \\
$\mathrm{AlN}$ & 0.427 & 0.237 & 0.211 & 0.129 \\
\hline
\end{tabular}

It has been established that the MCF rubber with $\mathrm{KI}+\mathrm{I}_{2}$ has a high electrical conductivity [1], given that $\mathrm{KI}+\mathrm{I}_{2}$ is easily ionized. In this case, the electric current in the cyclic voltammogram is larger. $\mathrm{SiC}$ is a promising compound semiconductor that has a high dielectric breakdown electric field strength. Therefore, the electric current in the cyclic voltammogram is the largest among them.

As seen from Figure 6(a), the area of the cyclic voltammogram's curve becomes typically larger after $\gamma$-irradiation. This indicates the possibility of enhancing power generation by $\gamma$-rays. In contrast, based on the study of cyclic voltammogram of $\gamma$-irradiation for $\mathrm{TiO}_{2}$ in plastic substrates [41], the electric current decreases. The result observed in Figure 6(a) is due to the electron jump presented in Figure 4(a) that occur in metal complex as well as $\mathrm{TiO}_{2}$.

In the case of $\mathrm{LiNbO}_{3}$ as shown in Figure 6(c), the shape of cyclic voltammogram's curve is different from that of the other dopants and the electric current temporarily decreases with the increase of the voltage. The cause may be as follows: $\mathrm{LiNbO}_{3}$ exhibits an electro-optic effect in that there is a correlation between light and the electromagnetic field. However, it has been established that the magnetization is due to indwelt inner magnetic cluster involved in the MCF liquid, in our previous study [9]. In the absence of a magnetic field, the magnetic cluster has a remnant magnetization and the magnetic field lines are closed in the cluster. However, the MCF liquid does not have remnant magnetization. The MCF rubber is produced with the MCF and many magnetic clusters exist in the MCF rubber. Therefore, the synergy between $\gamma$-rays, electric and magnetic fields is created by $\mathrm{LiNbO}_{3}$.

However, the shape of the cyclic voltammogram's curve due to $\gamma$-irradiation shown in Figure 6(a) is different from the one due to ultraviolet and visible light as shown in Figure 7, which was investigated in a previous study [4]. The MCF rubber sheet in Figure 7 consisted of $0.2 \mathrm{~g} \mathrm{TiO}_{2}, 0.6 \mathrm{~g} \mathrm{Ni}, 0.45 \mathrm{~g} \mathrm{MF}(\mathrm{W}-40)$, and $1.8 \mathrm{~g}$ NR-latex, and an electric field was held constant at $6 \mathrm{~V}$ voltage, and a $2.7 \mathrm{~A}$ electric current was applied to the stainless steel plates with a $1 \mathrm{~mm}$ gap for 10 min under atmospheric conditions and a magnet field of $312 \mathrm{mT}$. The MCF rubber was a sheet of solar cell rubber and inserted between the electrode metal 
and conductive transparent glass coated with $\mathrm{TiO}_{2}$. The MCF rubber did not formed sensor style like the MCF rubber sensor in the present study. Without using a dye and electrolyte, the MCF rubber sheet is photovoltaic. In the figure, the result in the absence of light is also shown. The shape of the cyclic voltammogram's curve shows an enhancement of the electric current around the largest plus and minus voltage ranges, which demonstrates the behavior of a photodiode. When the MCF rubber is a single sheet, it has photodiode effect. However, by deforming the MCF rubber to a sensor type such as the MCF rubber sensor in the present study, the photodiode effect disappears for $\gamma$-irradiation. In addition, the quantitative order of electric current to voltage in the case of $\gamma$-irradiation as shown in Figure 6 and Table 2 is larger than for the case of photovoltaic irradiation as shown in Figure 7. Thus, the power generated by $\gamma$-rays is greater than that generated by light.

\subsection{Mechanical Property}

When working in a nuclear plant building using instrument installed with rubber, etc., degradation of the rubber is serious problem. In general, ordinary rubber becomes hard after $\gamma$-irradiation so that the degradation can be ascertain according to the mechanical property. The established degradation property of rubber is isotropic [22] [23]. However, in the case of the rubber involved with metal complexes, the degradation of the rubber occurs via $\gamma$-irradiation, so that the degradation has been established based on the mechanical properties. The results on degradation are also isotropic [34] [35] [36]. Only few attempts have been made to date in terms of characterizing the mechanical property of anisotropic rubber such that used in the MCF rubber sensor. Figure 8 shows multiple tensile and compressive relations between strain and stress, comparing the results before and after $\gamma$-irradiation with a commercial, compact tensile testing machine (SL-6002, IMADA-SS Co. Ltd., Toyohasi, Japan). The MCF rubber sensor is elongated along the electrical wires and compressed transversely to the flat surface, which is the same as in Figure 6(a).

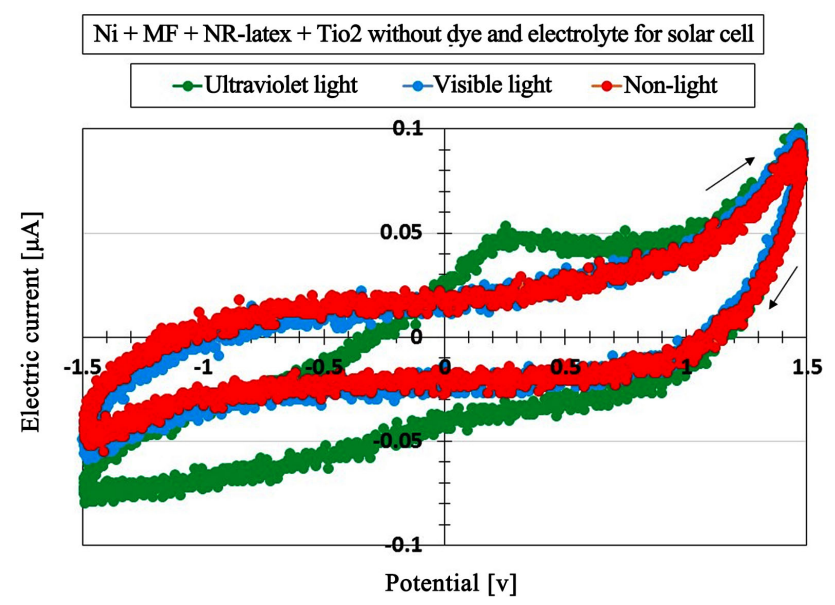

Figure 7. Cyclic voltammogram of MCF rubber as solar cell. 


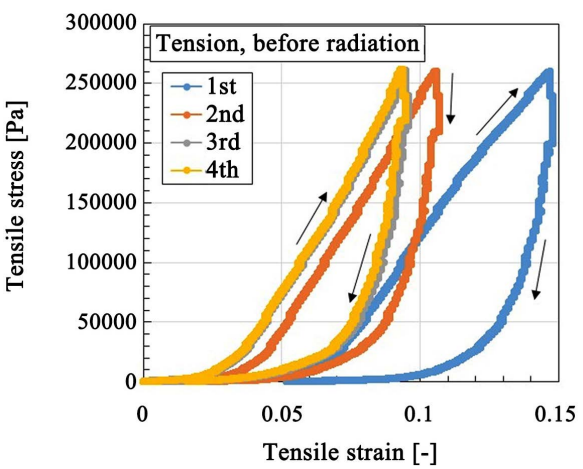

(a)

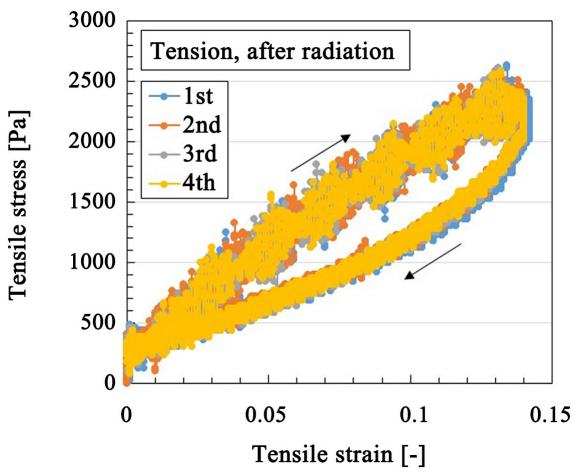

(b)

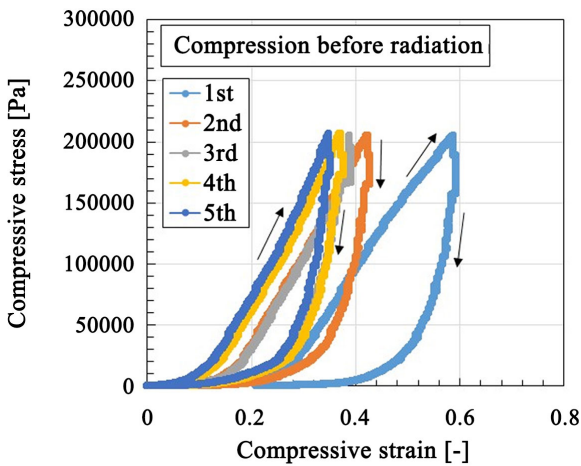

(c)

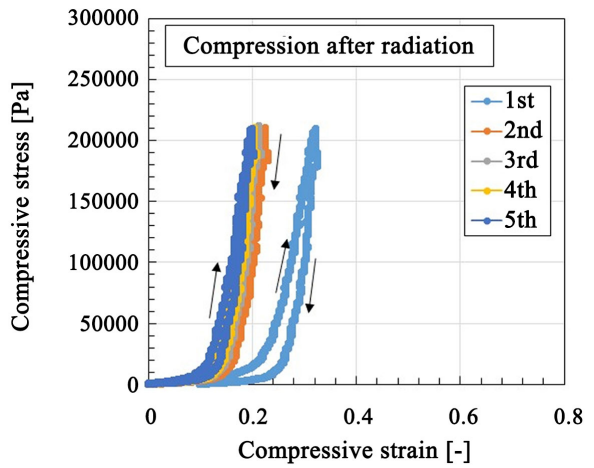

(d)

Figure 8. Relation between strain and stress at tension and compression of MCF rubber sensor: (a) and (b) for tension; (c) and (d) as for compression; (a) and (c) before $\gamma$-irradiation; (b) and (d) after $\gamma$-irradiation. 
This rubber exhibits the Mullins effect that the stress-strain responses have hysteresis curves and stress softening [1] [6], which can be seen in the ordinary rubber with fillers such as metal particles. Therefore, the MCF rubber sensor also exhibits the Mullins effect in both tension and compression before irradiation because of the existence of fillers such as $\mathrm{Fe}_{3} \mathrm{O}_{4}, \mathrm{Ni}, \mathrm{TiO}_{2}, \mathrm{Na}_{2} \mathrm{WO}_{4} \cdot 2 \mathrm{H}_{2} \mathrm{O}$. However, during tension after irradiation, the MCF rubber sensor becomes soft and the Mullins effect disappears. In contrast, during compression after irradiation, the MCF rubber sensor becomes hard and the Mullins effect weakens. The tendency to become soft during tension after irradiation and the anisotropy of the softness between the tension and compression are typical characteristics. The cause of these results can be potentially explained as discussed in the following.

In general, as indicated in other studies on ordinary rubber without a filler that is vulcanized using sulfur such as SBR [22], in blends of polybutadiene rubber and NR [24], and hydrogenated NBR [25], more C-C crosslinks are created than C-S crosslinks by $\gamma$-irradiation. As such, the rubber hardens. In this case, although some of $\mathrm{C}-\mathrm{C}$ crosslinks are divided into components, the created $\mathrm{C}-\mathrm{C}$ crosslinks are larger than the ones that are divided into components. The mechanism implies that the isoprene molecules can cross-link reciprocally via $\gamma$-irradiation. Considering this mechanism and the fact that the energy of $\gamma$-irradiation contributes to cross-linking, it is understood that the electromagnetic energy creates the cross-linking. The principle is the same as the case of our proposed electrolytic polymerization of the MCF rubber under the application of a magnetic field: due to the introduced electric energy, each isoprene molecule can cross-link reciprocally as shown in Equation (A1) in Appendix, which is presented in a previous study [1] [7]. An anionic isoprene molecule is represented by an equation as an ionized anion as a result of the jumping of electrons in " $b$ " in Figure 4(b). As a result, it can be asserted that the jumping electrons cause both the hardness associated with the $\gamma$-irradiation and the decrease of the Mullins effect. However, the hardness in the MCF rubber does not necessarily lead to degradation, as is the case in ordinary rubbers.

To investigate the hardness of the MCF rubber sensor created by $\gamma$-irradiation, we analyzed the Raman spectra of the MCF rubber sensor shown in Figure 8(a) before and after $\gamma$-irradiation, as shown in Figure 9. In this case, we can show that the fillers of $\mathrm{Fe}_{3} \mathrm{O}_{4}, \mathrm{Ni}, \mathrm{TiO}_{2}$ and the hydrate $\mathrm{Na}_{2} \mathrm{WO}_{4} \cdot 2 \mathrm{H}_{2} \mathrm{O}$ are inorganic substances so that they do not influence the Raman spectra at $1663 \mathrm{~cm}^{-1}$ and $1710 \mathrm{~cm}^{-1}$ ( $\mathrm{C}=\mathrm{C}$ stretching of the carbon double bonds of isoprene) and at 1000 $\mathrm{cm}^{-1}$ (C-C of joint between each isoprene), as shown in Figure A2 in Appendix. Therefore, we can estimate the change of the crosslinks of the rubber.

The characteristic peaks are at $1663 \mathrm{~cm}^{-1}$ and $1710 \mathrm{~cm}^{-1} ; 2852 \mathrm{~cm}^{-1}, 2915 \mathrm{~cm}^{-1}$ and $2960 \mathrm{~cm}^{-1}\left(\mathrm{CH}_{2}\right.$ stretching vibration of $\mathrm{C}-\mathrm{CH}_{2} \mathrm{CH}_{3}$ of isoprene); $3036 \mathrm{~cm}^{-1}$ (C-H stretching vibration of isoprene); in addition to a peak at $1000 \mathrm{~cm}^{-1}$. A comparison of the peak at $3036 \mathrm{~cm}^{-1}$ of $\mathrm{C}-\mathrm{H}$, which does not contribute to the $\mathrm{C}-\mathrm{C}$ crosslinks created by $\gamma$-irradiation, with the peaks at $1663 \mathrm{~cm}^{-1}$ and 1710 
$\mathrm{cm}^{-1}$ of $\mathrm{C}=\mathrm{C}$ and $1000 \mathrm{~cm}^{-1}$ of $\mathrm{C}-\mathrm{C}$ are presented in Table 3. The results indicate the typical characteristic that the quantity of $\mathrm{C}=\mathrm{C}$ and $\mathrm{C}-\mathrm{C}$ bonds decrease with $\gamma$-irradiation. This is different from the result that more $\mathrm{C}$-C crosslinks are created by $\gamma$-irradiation, as observed in ordinary rubber.

Therefore, to explain the experimental data shown in Figure 8, we must also consider another physical model, except for the cross-linking created by $\gamma$-irradiation, the interaction of anionic molecules and particles. As observed in Figure 10(a), the direction of application of the magnetic field during the production of the MCF rubber sensor is the same as that during the compression. Therefore, the direction of the long axis of the magnetic cluster like a needle [1], is the same as that during compression. In the case of compression, the MCF rubber sensor cannot be easily compressed because of the repulsive force between the magnetic clusters. In contrast, during tension, the MCF rubber sensor can be easily elongated because of the same repulsive force between the magnetic clusters. When subjected to $\gamma$-irradiation, particles and molecules are ionized as shown in Figure 4(b) and the repulsive force between the magnetic clusters or particles and molecules increases. Therefore, during compression, the repulsive forces increase from $t$ to $t$ ' as indicated in Figure 10(b) and the MCF rubber sensor cannot be easily compressed. In contrast, during tension, the repulsive force increases from $\mathrm{p}$ to $\mathrm{p}$ ' as indicated in Figure 10(b) and the MCF rubber sensor can be easily elongated. During both compression and tension, the MCF rubber sensor becomes stiff so that stress softening decreases, because of the increasing repulsive force.

Table 3. Comparison of spectra from Figure 9.

\begin{tabular}{ccc}
\hline & At 1663 and $1710 \mathrm{~cm}^{-1}$ of $\mathrm{C}=\mathrm{C}$ & At $1000 \mathrm{~cm}^{-1}$ of C-C \\
\hline Before Irradiation & 0.806 & 0.398 \\
After Irradiation & 0.764 & 0.183
\end{tabular}

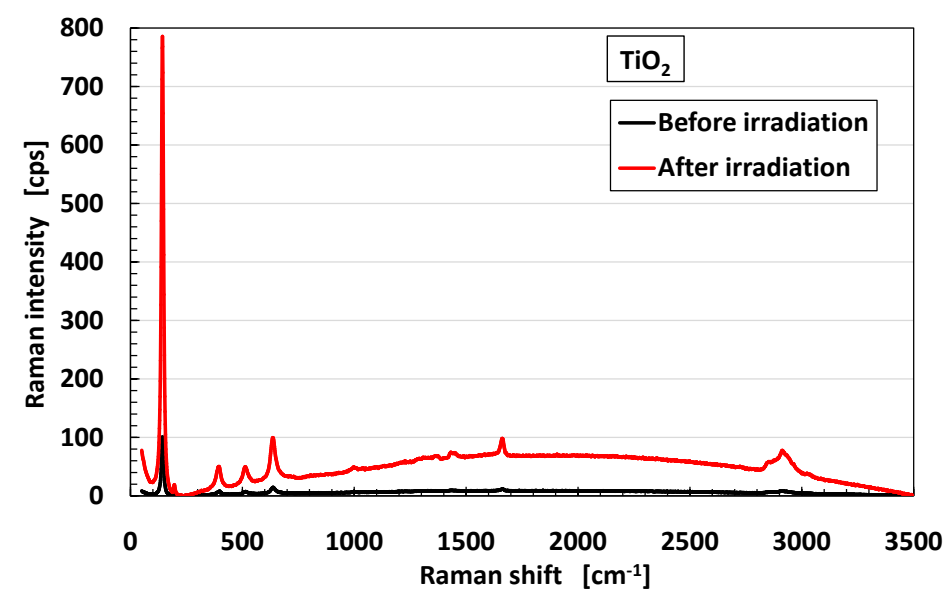

Figure 9. Raman spectra for the MCF rubber sensor comparing before and after $\gamma$-irradiation. 


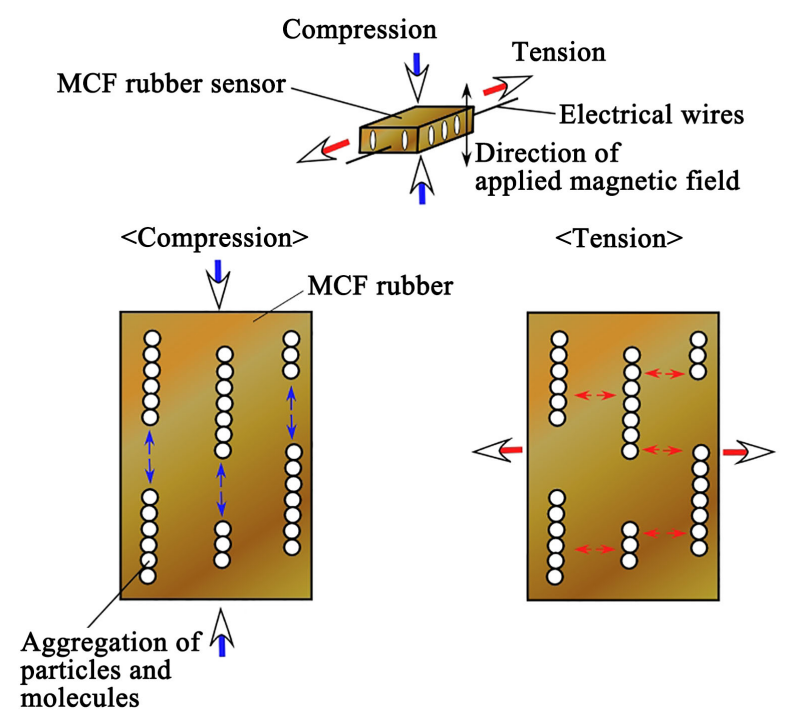

(a)

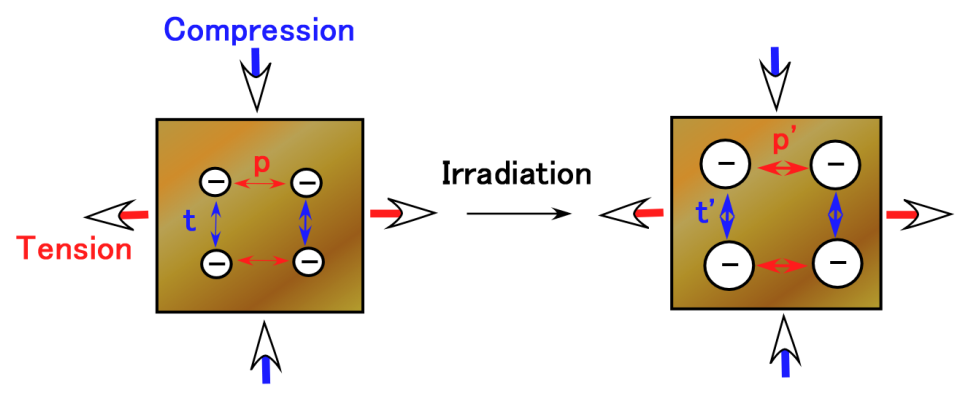

(b)

Figure 10. Schematic model showing the relationship between strain and stress during tension and compression of MCF rubber sensor; (b) shows the details for (a).

\section{Energy Harvesting}

Power generation using infrared rays as well as thermal sources, which is important in energy harvesting, was evaluated based on the induced voltage using a heater with graphite. It is necessary to use familiar instruments from our daily lives because energy harvesting is based on the exploitation of any available energy sources that are regularly encountered. As shown in Figure 11, the MCF rubber sensor was settled on air at a distance of $100 \mathrm{~mm}$ from a heater made from graphite so that it irradiated far-infrared waves with $900 \mathrm{~W}$ irradiation (DCTS-A091, Yamazen Co. Ltd., Tokyo, Japan). Simultaneously, the temperature in the vicinity of the MCF rubber sensor was also measured using an adjacent thermocouple. Figure 12 shows the change of the induced voltage of the MCF rubber sensor and air temperature with time for the far-infrared radiation. The MCF rubber sensor consisted of MCF rubber liquid with hydrate as $1 \mathrm{~g} \mathrm{Ni}$, $0.75 \mathrm{~g}$ MF (W-40), $3 \mathrm{~g}$ NR-latex, $3 \mathrm{~g}$ CR-latex (671A), $0.5 \mathrm{~g} \mathrm{TiO}_{2}$, and $0.5 \mathrm{~g}$ $\mathrm{Na}_{2} \mathrm{WO}_{4} \cdot 2 \mathrm{H}_{2} \mathrm{O}$, and MCF rubber without hydrate as $3 \mathrm{~g} \mathrm{Ni}, 0.75 \mathrm{~g} \mathrm{MF}(\mathrm{W}-40), 3$ g NR-latex, $3 \mathrm{~g}$ CR-latex $(671 \mathrm{~A})$, and $0.5 \mathrm{~g} \mathrm{TiO}_{2}$ with identical constituent and rubber size as shown in Figure 5(a). 


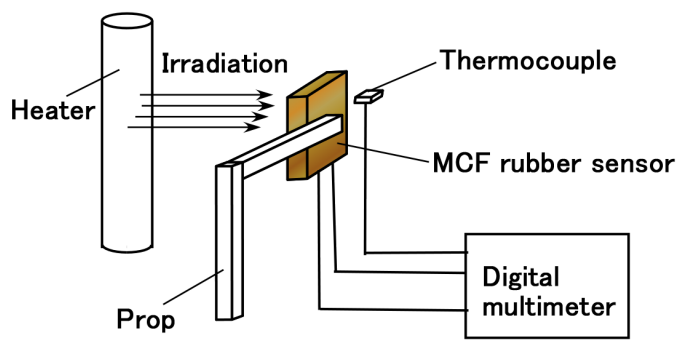

Figure 11. Schematic diagram of experiment on irradiation of MCF rubber sensor by infrared rays.

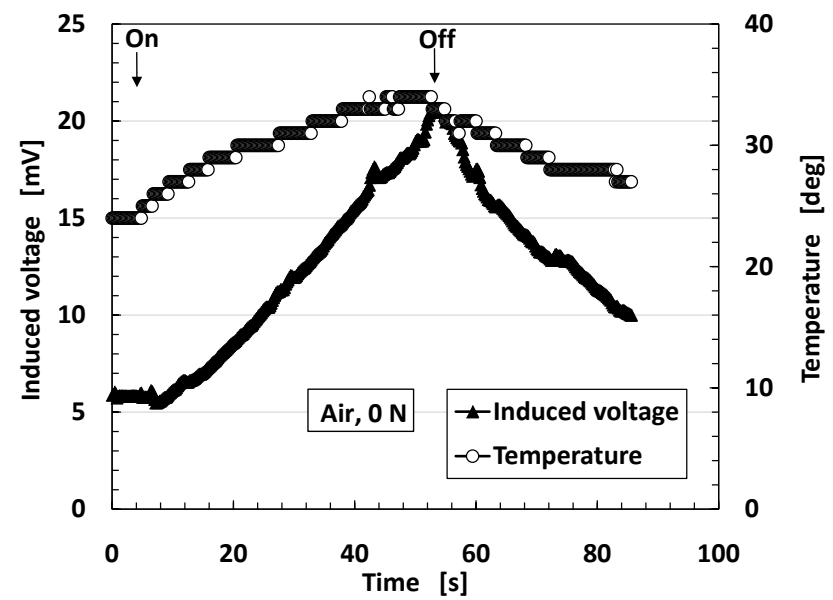

Figure 12. Change of induced voltage of MCF rubber sensor by irradiation with infrared rays.

In addition, for another thermal source as shown in Figure 13, when hot water with a temperature of $90^{\circ} \mathrm{C}$ and cool water at $5^{\circ} \mathrm{C}$ were poured into a vessel respectively, the copper plate placed on the vessel as a lid got warm and cool respectively. The change of the temperature of the copper plate with time was measured using an attached thermocouple. The MCF rubber sensor approached the copper plate very closely without touching it with a final separation of approximately $0.1 \mathrm{~mm}$. The change in the induced voltage of the MCF rubber sensor under stationary conditions was measured as a function of temperature. This experiment recreates the situation whereby a thermal sensor installed on a robot's hand or foot approaches a heat source. Figure 14 shows the change of the temperature of the copper plate and the induced voltage of the MCF rubber sensor with time. The MCF rubber sensor consisted of the MCF rubber liquid with hydrate as $1 \mathrm{~g} \mathrm{Ni}, 0.75 \mathrm{~g}$ MF (W-40), $3 \mathrm{~g}$ NR-latex, $3 \mathrm{~g}$ CR-latex (671A), 0.5 $\mathrm{g} \mathrm{TiO}_{2}$, and $0.5 \mathrm{~g} \mathrm{Na}_{2} \mathrm{WO}_{4} \cdot 2 \mathrm{H}_{2} \mathrm{O}$, and $\mathrm{MCF}$ rubber without hydrate as $3 \mathrm{~g} \mathrm{Ni}$, $0.75 \mathrm{~g}$ MF (W-40), 3 g NR-latex, 3 g CR-latex (671A), and $0.5 \mathrm{~g} \mathrm{TiO}_{2}$ in which the constituent, as well as the rubber size, was the same as those in Figure 5(a). As the temperature was increased and decreased, the induced voltage of the MCF rubber sensor also increased and decreased, respectively. The likely cause is that the MCF rubber sensor has a structure that consists of an MCF rubber between two thin wire electrodes. 


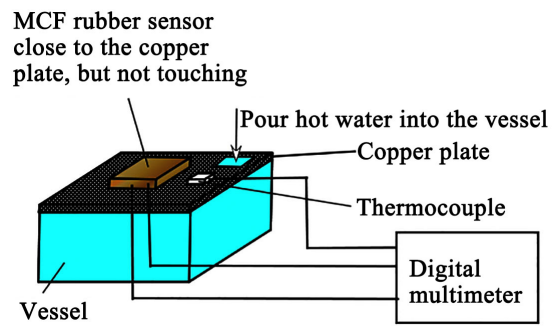

Figure 13. Schematic diagram of experiment of thermal source to MCF rubber sensor.

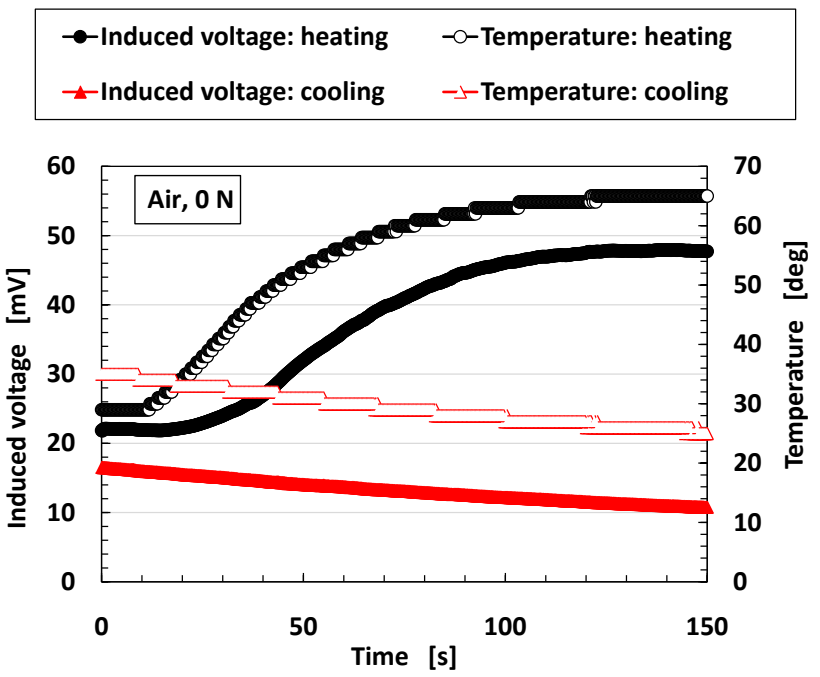

Figure 14. Change of induced voltage of MCF rubber sensor by heating and cooling.

Electrons are energized during the heating process and a voltage is induced due to the motion of the electrons. On the contrary, the motion of electrons is hindered in the case of cooling, and the voltage is consequently reduced. Thus, the MCF rubber sensor is established to be sensitive enough to be suitable for power generation with a thermal source.

Power generation by a microwave source is important in energy harvesting. This process was evaluated based on the induced voltage that resulted when the senor was subjected to a microwave source. As shown in Figure 15, the MCF rubber sensor was placed inside a microwave oven operating at a microwave frequency of $2.45 \mathrm{GHz}$. The settlement position was the middle of the bottom of the microwave oven such that the microwave intensely irradiated the MCF rubber sensor. Figure 16 shows the change of the induced voltage and electric current of the MCF rubber sensor with time during the irradiation process. The rubber sensor consisted of MCF rubber liquid with hydrate as $1 \mathrm{~g} \mathrm{Ni}, 0.75 \mathrm{~g}$ MF (W-40), 3 g NR-latex, $3 \mathrm{~g}$ CR-latex (671A), $0.5 \mathrm{~g} \mathrm{TiO}_{2}$, and $0.5 \mathrm{~g} \mathrm{Na}_{2} \mathrm{WO}_{4} \cdot 2 \mathrm{H}_{2} \mathrm{O}$, and MCF rubber without hydrate as $3 \mathrm{~g} \mathrm{Ni}, 0.75 \mathrm{~g}$ MF (W-40), $3 \mathrm{~g}$ NR-latex, $3 \mathrm{~g}$ CR-latex (671A), and $0.5 \mathrm{~g} \mathrm{TiO}_{2}$ with identical constituents and rubber size as shown in Figure 5(a). In contrast, in our previous study, we established the effect of microwaves on an MCF rubber sheet made of silicone oil rubber that was 


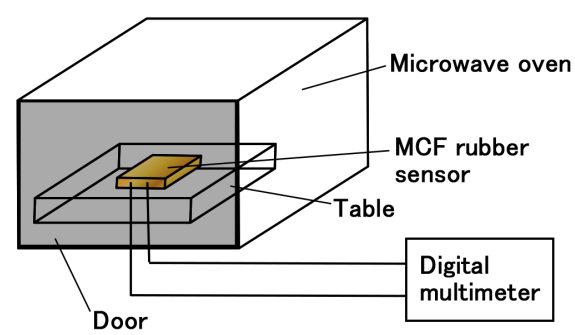

Figure 15. Schematic diagram of experiment for irradiation of MCF rubber sensor with microwaves.

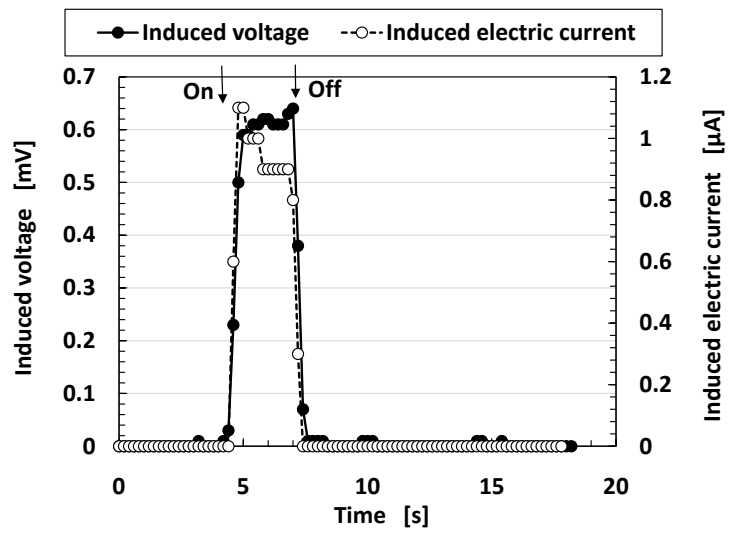

Figure 16. Change of induced voltage of MCF rubber sensor by irradiation of microwave.

solidified under ambience drying [47]; the power of the MCF rubber was generated by the incident microwaves. The MCF rubber sensor made with NR- and CR-rubbers also generated magnetoelectricity. Thus, the MCF rubber sensor was established to be suitable for power generation using a microwave source.

Based on the results for $\gamma$-irradiation, infrared rays as well as thermal and microwave sources that involved the photovoltaic effect of visible and ultraviolet light in previous studies [4] [10] [11] [12], the MCF rubber sensor has the potential to generate power using broad band electromagnetic waves, as shown in Figure A3 in the Appendix. With respect to the details of other regions of the electromagnetic spectrum, the feasible of using this sensor can be readily inferred.

\section{Conclusions}

For a robot with an installed sensor operating in a nuclear reactor building, the typical characteristics of the MCF rubber sensor are that it is sensible for $\gamma$-irradiation enough to create the radiation power generation and that it is not degraded by $\gamma$-irradiation. In addition, for sensing of various sources including solar, thermal, etc., the MCF rubber sensor is sensitive to broad band electromagnetic waves from the small wave length around $\gamma$-irradiation to the one around microwave oven, and as such can be applied to energy harvesting during broad band electromagnetic waves. 
Regarding $\gamma$-irradiation, there is a temporary enhancement of the induced voltage during the initial irradiation and a subsequent fine oscillation, which can be explained by the physical model of electrons jumping from an inner shell and sequential avalanche of adjacent electrons. The MCF rubber sensor with $\mathrm{TiO}_{2}$ and metal complex hydrate $\mathrm{Na}_{2} \mathrm{WO}_{4} \cdot 2 \mathrm{H}_{2} \mathrm{O}$ has the potential to generate power when subjected to $\gamma$-irradiation. It has anisotropic mechanical properties and Mullins effect decreases when it is irradiated. Specifically, it is easily elongated along the direction of the wire electrodes, creating magnetic cluster alignments; however, hardening occurs along the transverse direction. The $\gamma$-irradiation effect on the mechanical property can be explained according to the physical model of the correlation of anionic molecules and particles. The shape of the cyclic voltammogram's curve is different depending on the kind of dopants involved in the MCF rubber sensor. By deforming the MCF rubber to a sensor type such as the MCF rubber sensor, the photodiode effect disappears with $\gamma$-irradiation. Degradation due to $\gamma$-irradiation does not necessarily occur in the MCF rubber sensor.

Regarding energy harvesting, the MCF rubber sensor has the potential for power generation as established from its sensitivity to various sources encountered daily. We can utilize any instruments that are familiar in our daily lives because energy harvesting involves the exploitation of energy sources that are readily available and accessible. The MCF rubber sensor is sensitive to infrared irradiation and thermal source. Based on the sensitivity to microwaves and considering $\gamma$-irradiation and photovoltaic effects, the sensor is not only sensitive to broad band electromagnetic waves, but also suitable for energy harvesting.

Based on the present and previous studies, the MCF rubber sensor was established to be effective in a wide variety of engineering applications. However, there remains the issue of stability of the sensor. This problem will be addressed in a consecutive report.

\section{Acknowledgments}

This work was supported in part by JSPS KAKENHI Grant Number JP 18K04040. We are very grateful for this support. We would like to thank Yoda, I., and technical staff of Cobalt-60 Irradiation Facility of Laboratory for Advanced Nuclear Energy in Tokyo Inst. Tech. in Japan for the irradiation support provided. We also would like to thank Kazuya Shimada, graduate school student of Tokyo Inst. Tech. in Japan for helpful suggestions.

\section{Conflicts of Interest}

The authors declare no conflicts of interest regarding the publication of this paper.

\section{References}

[1] Shimada, K. and Saga, N. (2016) Mechanical Enhancement of Sensitivity in Natural Rubber Using Electrolytic Polymerization Aided by a Magnetic 
Field and MCF for Application in Haptic Sensors. Sensors, 16, 1521. https://doi.org/10.3390/s16091521

[2] Shimada, K., Mochizuki, O. and Kubota, Y. (2017) The Effect of Particles on Electrolytically Polymerized Thin Natural MCF Rubber for Soft Sensors Installed in Artificial Skin. Sensors, 17, 896. https://doi.org/10.3390/s17040896

[3] Shimada, K. and Saga, N. (2017) Development of a Hybrid Piezo Natural Rubber Piezoelectricity and Piezoresistivity Sensor with Magnetic Clusters Made by Electric and Magnetic Field Assistance and Filling with Magnetic Compound Fluid. Sensors, 17, 346. https://doi.org/10.3390/s17020346

[4] Shimada, K. (2017) Elastic Dry-Type Solar Cell Rubber with Photovoltaics and Piezoelectricity for Compressive Sensing. Presented at the 4th International Electronic Conference on Sensors and Applications, 2, 112.

https://doi.org/10.3390/ecsa-4-04890

[5] Shimada, K. and Saga, N. (2016) Detailed Mechanism and Engineering Applicability of Electrolytic Polymerization Aided by a Magnetic Field in Natural Rubber by Mechanical Approach for Sensing (Part 1): The Effect of Experimental Conditions on Electrolytic Polymerization. World Journal of Mechanics, 6, 357-378.

https://doi.org/10.4236/wjm.2016.610026

[6] Shimada, K. and Saga, N. (2016) Detailed Mechanism and Engineering Applicability of Electrolytic Polymerization Aided by a Magnetic Field in Natural Rubber by Mechanical Approach for Sensing (Part 2): Other and Intrinsic Effects on MCF Rubber Property. World Journal of Mechanics, 6, 379-395.

https://doi.org/10.4236/wjm.2016.610027

[7] Shimada, K. (2017) Enhancement of MCF Rubber Utilizing Electric and Magnetic Fields, and Clarification of Electrolytic Polymerization. Sensors, 17, 767. https://doi.org/10.3390/s17040767

[8] Shimada, K., Akagami, Y., Fujita, T., Miyazaki, T., Kamiyama, S. and Shibayama, A. (2002) Characteristics of MCF (Magnetic Compound Fluid) in a Rotating Rheometer. Journal of Magnetism and Magnetic Materials, 252, 235-237. https://doi.org/10.1016/S0304-8853(02)00646-7

[9] Shimada, K., Miyazaki, T., Shibayama, A. and Fujita, T. (2003) Extraction of Magnetic Clusters Self-Assembled by a Magnetic Field. Smart Materials and Structures, 12, 297-303. https://doi.org/10.1088/0964-1726/12/2/318

[10] Shimada, K. (2018) Elastic MCF Rubber with Photovoltaics and Sensing for Use as Artificial or Hybrid Skin (H-Skin): 1st Report on Dry-Type Solar Cell Rubber with Piezoelectricity for Compressive Sensing. Sensors, 18, 1841.

https://doi.org/10.3390/s18061841

[11] Shimada, K. (2018) Elastic MCF Rubber with Photovoltaics and Sensing on Hybrid Skin (H-Skin) for Artificial Skin by Utilizing Natural Rubber: 2nd Report on Effect of Tension and Compression on Properties of Hybrid Photo- and Piezo-Electricity in Wet-Type Solar Cell Rubber. Sensors, 18, 1848. https://doi.org/10.3390/s18061848

[12] Shimada, K. (2018) Elastic MCF Rubber with Photovoltaics and Sensing for Use as Artificial or Hybrid Skin (H-Skin): Third Report on Electric Charge and Storage under Tension and Compression. Sensors, 18, 1853.

https://doi.org/10.3390/s18061853

[13] Shimada, K., Kikura, H., Takahashi, H. and Ikeda, R. (2019) Novel Adhesion Technique Using Metallic or Non-Metallic Hydrous Oxide of Metal Complexes Involving Magnetic Compound Fluid Rubber under Electrolytic Polymerization and 
Magnetic Field for Producing Sensors. Sensors, 19, 689. https://doi.org/10.3390/s19030689

[14] Kim, J.H. (2014) Reactor Inspection System. Nuclear Plant Journal, 32, 40-42.

[15] Popescu, C., Rosca-Fartat, G. and Pana, N. (2017) Details of Operations Reformed by the Remote Control Robot (Concept) to the Horizontal Fuel Channel during Decommissioning Phase of Nuclear Reator Calandria Structure. Part 1: Outside Operation. Fiability and Durability, 1, 316-323.

[16] Grelaud, A., Mitra, P., Xie, M. and Chen, R. (2018) A Dynamic Fusion System for Fast Nuclear Source Detection and Localization with Mobile Sensor Networks. Applied Stochastic Models in Business and Industry, 34, 4-19.

https://doi.org/10.1002/asmb.2293

[17] Tamura, A., Endo, M., Kono, N., Okazawa, H., Okido, S., Kogia, M., Zhong, C., Fabre, E., Croxford, A.J. and Wilcox, P.D. (2019) A Non-Contact Ultrasonic Sensor for Pipe-Wall Thinning Inspection of Nuclear Power Plants. AIP Conference Proceedings, 2102, Article ID: 060009. https://doi.org/10.1063/1.5099799

[18] Hu, G., Qin, B. and Bo, H. (2018) Control Rod Position Measurement with Helix-Electrode Capacitance Sensor in Nuclear Heating Reactor. Annals of Nuclear Energy, 120, 788-797. https://doi.org/10.1016/j.anucene.2018.06.038

[19] Volodymyr, G., Valery, S., Aoki, T., Koike, A. and Pecharapa, W. (2018) Development of CdTe-Based Nuclear Radiation Sensors and Related Devices. AIP Conference Proceedings, 2010, Article ID: 020012.

[20] Min, D., Yan, C, Huang, Y., Li, S. and Ohki, Y. (2017) Dielectric and Carrier Transport Properties of Silicone Rubber Degraded by Gamma Irradiation. Polymers, 9, 533. https://doi.org/10.3390/polym9100533

[21] Mushfequr, R.M., Sharmin, N., Khan, R.A., Dey, K. and Haque, M.E. (2012) Studies on the Mechanical and Degradation Properties of Jute Fabric-Reinforced Natural Rubber Composite: Effect of Gamma Radiation. Journal of Thermoplastic Composite Materials, 25, 249-264. https://doi.org/10.1177/0892705711405559

[22] Wang, Q., Wang, F. and Cheng, K. (2009) Effect of Crosslink Density on Some Properties of Electron Beam-Irradiated Styrene-Butadiene Rubber. Radiation Physics and Chemistry, 78, 1001-1005. https://doi.org/10.1016/j.radphyschem.2009.06.001

[23] Liu, Y., Zhou, C. and Feng, S. (2012) Effects of $\gamma$-Ray Radiation on the Properties of Fluorosilicone Rubber. Materials Letters, 78, 110-112. https://doi.org/10.1016/j.matlet.2012.03.065

[24] Wang, W., Jiao, Y., Cheng, A., Lu, Y., Liu, J., Zeng, X., Wang, L., Zhang, Y. and Guo, Y. (2017) Enhanced Thermal Stability of Gamma Radiation Vulcanized Polybutadiene Rubber (PBR)/Natural Rubber (NR) Blends with Sulfur Added. Materials Letters, 186, 186-188. https://doi.org/10.1016/j.matlet.2016.09.128

[25] Dai, P., Cheng, A., Zhao, X., Jiao, Y., Lu, Y., Wang, L. and Zeng, X. (2018) Fabrication and Mechanical Properties of $\gamma$-Ray Radiation Vulcanized HNBR with High Recovery after Compression. Radiation Physics and Chemistry, 151, 271-275. https://doi.org/10.1016/j.radphyschem.2018.03.012

[26] Zhang, J.D., Fung, S., Bin, L.L. and Jun, L.Z. (2002) Ti ion Valence Variation Induced by Ionizing Radiation at $\mathrm{TiO}_{2} / \mathrm{Si}$ Interface. Surface and Coatings Technology, 158-159, 238-241. https://doi.org/10.1016/S0257-8972(02)00218-9

[27] Chitose, N., Ueta, S., Seino, S. and Yamamoto, T.A. (2003) Radiolysis of Aqueous Phenol Solutions with Nanoparticles. 1. Phenol Degradation and TOC Removal in Solutions Containing $\mathrm{TiO}_{2}$ Induced by UV, $\gamma$-Ray and Electron Beams. Chemos- 
phere, 50, 1007-1013. https://doi.org/10.1016/S0045-6535(02)00642-2

[28] Nagaishi, R., Yoshida, Z., Yamada, R. and Hatano, Y. (2006) Radiation-Induced Catalytic Reduction of Chromium (VI) in Aqueous Solution Containing $\mathrm{TiO}_{2}, \mathrm{Al}_{2} \mathrm{O}_{3}$ or $\mathrm{SiO}_{2}$ Fine Particles. Radiation Physics and Chemistry, 75, 1051-1054. https://doi.org/10.1016/j.radphyschem.2006.01.005

[29] Bzdon, S., Goralski, J., Maniukiewicz, W., Perkowski, J., Rogowski, J. and Nicze, M.S. (2012) Radiation-Induced Synthesis of Fe-Doped $\mathrm{TiO}_{2}$ : Characterization and Catalytic Properties. Radiation Physics and Chemistry, 81, 322-330. https://doi.org/10.1016/j.radphyschem.2011.10.023

[30] Qian, G., Baccaro, S., Guerra, A., Xiaoluan, L., Shuanglong, Y., Iurlaro, G. and Chen, G. (2007) Gamma Irradiation Effects on ZnO-Based Scintillating Glasses Containing $\mathrm{CeO}_{2}$ and/or $\mathrm{TiO}_{2}$. Nuclear Instruments and Methods in Physics Research Section $B, 262,276-280$.

[31] Ayta, W.E.F., Silva, V.A., Cano, N.F., Silva, M.A.P. and Dantas, N.O. (2011) Thermoluminescence, Structural and Magnetic Properties of a $\mathrm{Li}_{2} \mathrm{O}-\mathrm{B}_{2} \mathrm{O}_{3}-\mathrm{Al}_{2} \mathrm{O}_{3}$ Glass System Doped with $\mathrm{LiF}$ and $\mathrm{TiO}_{2}$. Journal of Luminescence, 131, 1002-1006.

[32] Essehli, R., Crumiere, F., Blain, G., Vandenborre, J., Pottier, F., Grambow, B., Fattahi, M. and Mostafavi, M. (2011) $\mathrm{H}_{2}$ Production by $\gamma$ and He Ions Water Radiolysis, Effect of Presence $\mathrm{TiO}_{2}$ Nanoparticles. International Journal of Hydrogen Energy, 36, 14342-14348. https://doi.org/10.1016/j.ijhydene.2011.05.136

[33] Kavanoz, H.B., Yagci, O., Yalcin, Z., Icelli, O., Altindal, A., Okutan, M. and Mann, K.S. (2014) Photon Parameters of $\gamma$-Rays Sensing Properties of Some Thick Oxide Films. Vacuum, 101, 238-245. https://doi.org/10.1016/j.vacuum.2013.09.001

[34] Ashour, A.H., Saad, H.M. and Ibrahim, M.M. (2006) Electrical Conductivity for Irradiated, Grafted Polyethylene and Grafted Polyethylene with Metal Complex. Egyptian Journal of Solids, 29, 351-362.

[35] Shqer, S.A., Melha, K.S.A., Hazmi, G.A.A.A., Saad, F.A. and Metwaly, N.M.E. (2014) Spectral Studies on a Series of Metal Ion Complexes Derived from Pyrimidine Nucleus, TEM, Biological and $\gamma$-Irradiation Effect. Spectrochimica Acta Part A: Molecular and Biomolecular Spectroscopy, 132, 751-761.

https://doi.org/10.1016/j.saa.2014.05.084

[36] Huang, W., Yang, W., Ma, Q., Wu, J., Fan, J. and Zhang, K. (2016) Preparation and Characterization of $\gamma$-Ray Radiation Shielding $\mathrm{PbWO}_{4} / \mathrm{EPDM}$ Composite. Journal of Radioanalytical and Nuclear Chemistry, 309, 1097-1103.

https://doi.org/10.1007/s10967-016-4713-9

[37] Miyano, M., Ono, S., Hishida, M., Yasunaga, D.T., Fujisawa, K. and Takamasa, T. (2005) ECP Decrease of Ceramic Coated Stainless Steel by Radiation Induced Surface Activation. Annual Meeting of The Atomic Energy Society of Japan, Hiratsuka, Japan, 29-31 March 2005, 437. (In Japanese)

[38] Dohshi, S., Anpo, M., Okuda, S. and Kojima, T. (2005) Effect of $\gamma$-Ray Irradiation on the Wettability of $\mathrm{TiO}_{2}$ Single Crystals. Topics in Catalysis, 35, 327-330. https://doi.org/10.1007/s11244-005-3841-1

[39] Tamura, K., Ohko, Y., Kawamura, H., Yoshikawa, H., Tatsuma, T., Fujishima, A. and Mizukim J. (2007) X-Ray Induced Photoelectrochemistry on $\mathrm{TiO}_{2}$. Electrochimica Acta, 52, 6938-6942. https://doi.org/10.1016/j.electacta.2007.05.011

[40] Ito, D., Nishi, D. and Saito, Y. (2014) Effect of Ultraviolet and Radiation on Surface Wettability. Japanese Journal of Multiphase Flow, 27, 555-561. (In Japanese) https://doi.org/10.3811/jjmf.27.555

[41] Abunahla, H., Jaoude, M.A., O’Kelly, C.J. and Mohammad, B. (2016) Sol-Gel/Drop- 
Coated Micro-Thick $\mathrm{TiO}_{2}$ Memristors for $\square \gamma$-Ray Sensing. Materials Chemistry and Physics, 184, 72-81.

https://doi.org/10.1016/j.matchemphys.2016.09.027

[42] Jia, H., Zhu, J., Debeli, D.K., Li, Z. and Guo, J. (2018) Solar Thermal Energy Harvesting Properties of Spacer Fabric Composite Used for Transparent Insulation Materials. Solar Energy Materials and Solar Cells, 174, 140-145. https://doi.org/10.1016/j.solmat.2017.08.039

[43] Noh, J.S. (2016) Conductive Elastomers for Stretchable Electronics, Sensors and Energy Harvesters. Polymers, 8, 123. https://doi.org/10.3390/polym8040123

[44] Chen, X., He, J., Song, L., Zhang, Z., Tian, Z., Wen, T., Zhai, C., Chen, Y., Cho, J., Chou, X. and Xue, C. (2018) Flexible One-Structure Arched Triboelectric Nanogenerator Based on Common Electrode for High Efficiency Energy Harvesting and self-Powered Motion Sensing. AIP Advances, 8, Article ID: 045022.

https://doi.org/10.1063/1.5027659

[45] Kaur, K.P., Upadhyaya, T., Palandoken, M. and Gocen C. (2019) Ultrathin Dual-Layer Triple-Band Flexible Microwave Metamaterial Absorber for Energy Harvesting Applications. International Journal of RF and Microwave Computer-Aided Engineering, 29, e21646. https://doi.org/10.1002/mmce.21646

[46] Wu, F., Li, C., Yin, Y., Cao, R., Li, H., Zhang, X., Zhao, S., Wang, J., Wang, B., Xing, Y. and Du, X. (2019) A Flexible, Lightweight, and Wearable Triboelectric Nanogenerator for Energy Harvesting and Self-Powered Sensing. Advanced Materials Technologies, 4, Article ID: 1800216. https://doi.org/10.1002/admt.201800216

[47] Zheng, Y. and Shimada, K. (2009) Basic Study on Usefulness of Magnetic Compound Fluid (MCF) Rubber as Material for Microwave Heating. Journal of Solid Mechanics and Materials Engineering, 3, 158-166.

https://doi.org/10.1299/jmmp.3.158

[48] Ikeda, R., Shimada, K., Takahashi H. and Kikura., H. (2019) Electric Potential Characteristics of MCF Rubber Sensor under Radiation Environment. Proceedings of 31 th Symposium on Electromagnetics and Dynamics (SEAD31), 31, 23C4-5. (In Japanese) 


\section{Appendix}

All MCF rubber sensors used in this report were made using our proposed adhesion technique detailed in our previous study [13]. Based on the adhesion technique using a metal complex hydrate in the MCF rubber latex (which is shown as "MCF rubber liquid with hydrate" in the figure) and a magnetic field under electrolytic polymerization as shown in Figure A1, thin metal electrodes wires were adhered between two electrolytically polymerized MCF rubbers without hydrate. In all the procedures for electrolytic polymerization, a static $312 \mathrm{mT}$ magnetic field was applied using permanent magnets as paired opposites with a constant electric field at $6 \mathrm{~V}$ and $2.7 \mathrm{~A}$ under atmospheric conditions.

Each isoprene molecule is cross-link to anionic isoprene molecule as shown in Equation (A1), and the mechanism has been presented in detail in our previous study [1] [7].

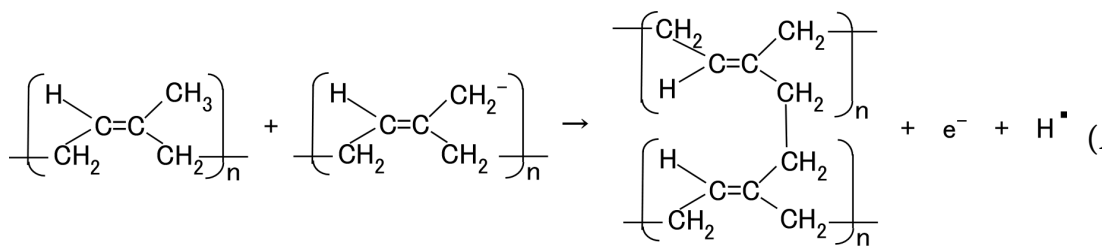

Figure A2 shows the Raman spectra of a liquid of mixed NR-latex and CR-latex, MCF rubber liquid ( $\mathrm{MF}+\mathrm{Ni}+\mathrm{NR}$-latex), and powder of hydrate $\mathrm{Na}_{2} \mathrm{WO}_{4} \cdot 2 \mathrm{H}_{2} \mathrm{O}$, respectively. The arrows in the figure indicate the Raman shift of $\mathrm{C}-\mathrm{C}$ and the one of the $\mathrm{C}=\mathrm{C}$. In the Raman spectra at $\mathrm{C}-\mathrm{C}$ and $\mathrm{C}=\mathrm{C}$, the spectrum of any substance cannot be confirmed to be amassed.

Figure A3 shows the well-known broad-band electromagnetic waves and the associated wave length.

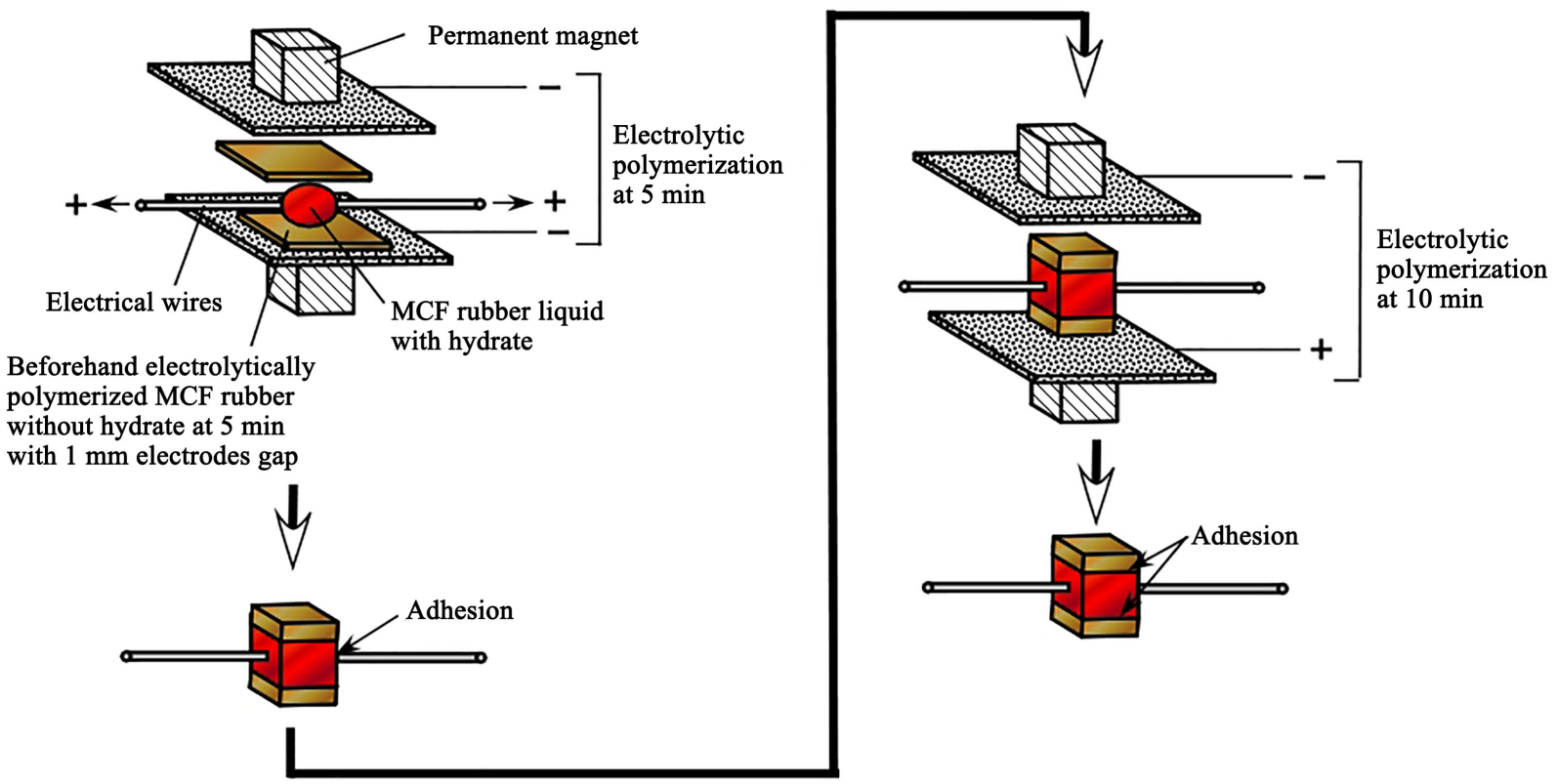

Figure A1. Production procedure for MCF rubber sensor with thin electric wires [13]. 


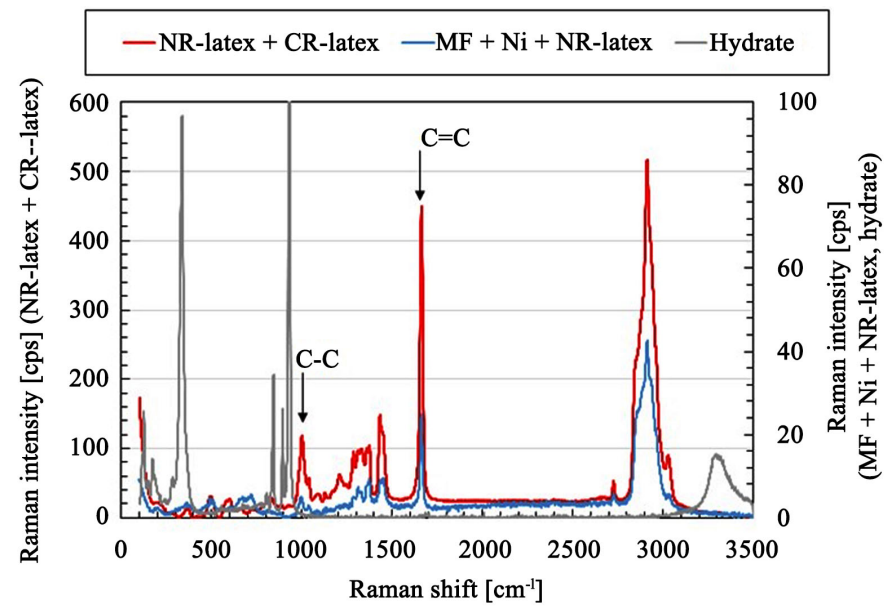

Figure A2. Raman spectroscopy spectra of the rubber liquid, MCF rubber liquid and hydrate powder: 3 g NR-latex +3 g CR-latex; 0.75 g $\mathrm{MF}+3 \mathrm{~g} \mathrm{Ni}+3 \mathrm{~g}$ NR-latex; hydrate $\mathrm{Na}_{2} \mathrm{WO}_{4} \cdot 2 \mathrm{H}_{2} \mathrm{O}$.

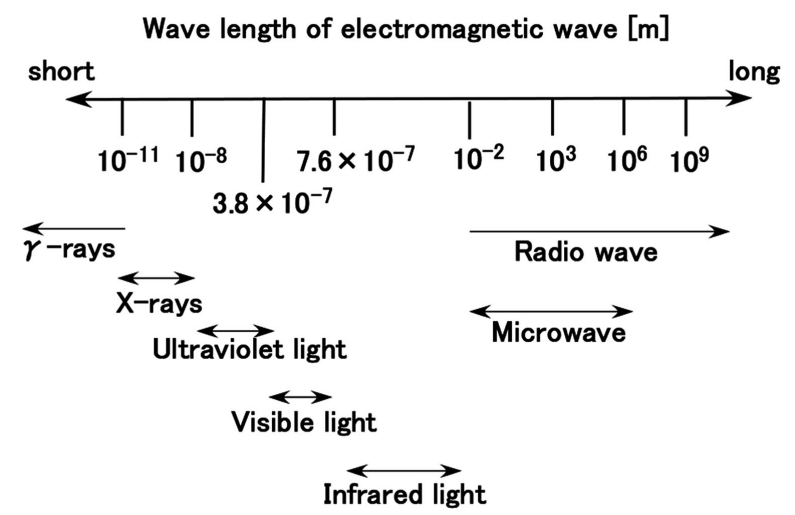

Figure A3. Broad band electromagnetic waves and the associated wave length. 